This is a post-peer-review, pre-copyedit version of an article published in International Journal of Precision Engineering and Manufacturing-Green Technology. The final authenticated version is available online at: https://doi.org/10.1007/s40684-019-00038-z 


\section{International Journal of Precision Engineering and Manufacturing-Green Technology}

\section{Investigation of thermal-related effects in Hot SPIF of Ti-6Al-4V alloy \\ --Manuscript Draft--}

\begin{tabular}{|c|c|}
\hline Manuscript Number: & JPGT-D-18-00027R4 \\
\hline Full Title: & Investigation of thermal-related effects in Hot SPIF of Ti-6AI-4V alloy \\
\hline Article Type: & Regular Paper \\
\hline Funding Information: & $\begin{array}{l}\text { Seventh Framework Programme } \\
(266208)\end{array}$ \\
\hline Abstract: & $\begin{array}{l}\text { The present work focuses on a new approach to hot form hard-to-work materials by } \\
\text { Single Point Incremental Forming (SPIF) technology using a global heating of the } \\
\text { sheet. A set of trials was carried out in order to identify the optimum temperature cycles } \\
\text { to minimize geometric distortions associated to each process stage on the fabrication } \\
\text { of parts made of Ti- } 6 \mathrm{Al}-4 \mathrm{~V} \text {. On the one hand, heating trials allowed defining the optimal } \\
\text { procedure to improve the temperature distribution homogeneity along the sheet and } \\
\text { consequently to minimize its thermal distortion previous to the forming stage. On the } \\
\text { other hand, the influence of both working temperature and the applied cooling on the } \\
\text { geometric accuracy was evaluated by means of SPIF trials. For this purpose, a generic } \\
\text { asymmetric design with typical aeronautical features was used. These trials pointed out } \\
\text { that high forming temperatures allow reducing significantly the material springback } \\
\text { whereas a controlled cooling (with an intermediate stress relief treatment) minimizes } \\
\text { both the distortion of the part during the cooling and the mechanical stresses } \\
\text { accumulated on the clamping system. Furthermore, the work includes a post-forming } \\
\text { material evaluation to determinate the influence of the employed processing conditions } \\
\text { on microcracks, alpha-case layer, microstructure and hardness. }\end{array}$ \\
\hline Corresponding Author: & $\begin{array}{l}\text { Mikel Ortiz } \\
\text { Tecnalia Research \& Innovation } \\
\text { SPAIN }\end{array}$ \\
\hline \multicolumn{2}{|l|}{$\begin{array}{l}\text { Corresponding Author Secondary } \\
\text { Information: }\end{array}$} \\
\hline Corresponding Author's Institution: & Tecnalia Research \& Innovation \\
\hline \multicolumn{2}{|l|}{$\begin{array}{l}\text { Corresponding Author's Secondary } \\
\text { Institution: }\end{array}$} \\
\hline First Author: & Mikel Ortiz \\
\hline \multicolumn{2}{|l|}{ First Author Secondary Information: } \\
\hline \multirow[t]{4}{*}{ Order of Authors: } & Mikel Ortiz \\
\hline & Mariluz Penalva \\
\hline & Edurne Iriondo \\
\hline & Luis Norberto López de Lacalle \\
\hline \multicolumn{2}{|c|}{ Order of Authors Secondary Information: } \\
\hline Author Comments: & $\begin{array}{l}\text { San Sebastian (Spain), January 24, } 2019 \\
\text { Dear Sung-Hoon Ahn, } \\
\text { I would like to thank you for accepting my manuscript entitled: } \\
\text { "Investigation of thermal-related effects in Hot SPIF of Ti-6Al-4V alloy", } \\
\text { Taking into account your comments and suggestions, I have modified the following } \\
\text { points in the final version of the manuscript: }\end{array}$ \\
\hline
\end{tabular}




\begin{tabular}{|c|c|}
\hline & $\begin{array}{l}\text {-Two relevant references of the IJPEM journal have been included in the final version } \\
\text { (ref. } 2 \text { and ref. 24). Regarding the JPGT, a relevant paper related to the topic of the } \\
\text { present manuscript had already been included (ref. 11). } \\
\text { •The box frame of several figures has been removed. } \\
\text { Yours Sincerely, } \\
\text { Mikel Ortiz Edesa } \\
\text { mikel.ortiz@tecnalia.com } \\
\text { M +34650984933 } \\
\text { Tecnalia Research \& Innovation } \\
\text { Parque Científico y Tecnológico de Gipuzkoa } \\
\text { Mikeletegi Pasealekua, } 7 \\
\text { E-20009 Donostia-San Sebastián - Gipuzkoa (Spain) }\end{array}$ \\
\hline Response to Reviewers: & $\begin{array}{l}\text { Taking into account your comments and suggestions, I have modified the following } \\
\text { points in the final version of the manuscript: } \\
\text {-Two relevant references of the IJPEM journal have been included in the final version } \\
\text { (ref. } 2 \text { and ref. 24). Regarding the JPGT, a relevant paper related to the topic of the } \\
\text { present manuscript had already been included (ref. 11). } \\
\text {-The box frame of several figures has been removed. }\end{array}$ \\
\hline
\end{tabular}



ARTICLE TYPE

\title{
Investigation of thermal-related effects in Hot SPIF of Ti-6Al-4V alloy
}

\author{
Mikel Ortiz ${ }^{1, \#}$, Mariluz Penalva1, Edurne Iriondo² and Luis Norberto López de Lacalle ${ }^{2}$ \\ 1 Advanced Manufacturing Area, Tecnalia Research \& Innovation, Paseo Mikeletegi 7-Parque Tecnológico E-20009 Donostia-San Sebastian, Spain \\ 2 Department of Mechanical Engineering, University of the Basque Country, 48013 Bilbao, Spain \\ \# Corresponding Author / E-mail: mikel.ortiz@tecnalia.com, TEL: +34-946-430-850
}

KEYWORDS: Ti-6Al-4V, Incremental forming, Global Heating, Heating equipment, Temperature cycles, Geometric accuracy

\begin{abstract}
The present work focuses on a new approach to hot form hard-to-work materials by Single Point Incremental Forming (SPIF) technology using a global heating of the sheet. A set of trials was carried out in order to identify the optimum temperature cycles to minimize geometric distortions associated to each process stage on the fabrication of parts made of Ti-6Al-4V. On the one hand, heating trials allowed defining the optimal procedure to improve the temperature distribution homogeneity along the sheet and consequently to minimize its thermal distortion previous to the forming stage. On the other hand, the influence of both working temperature and the applied cooling on the geometric accuracy was evaluated by means of SPIF trials. For this purpose, a generic asymmetric design with typical aeronautical features was used. These trials pointed out that high forming temperatures allow reducing significantly the material springback whereas a controlled cooling (with an intermediate stress relief treatment) minimizes both the distortion of the part during the cooling and the mechanical stresses accumulated on the clamping system. Furthermore, the work includes a post-forming material evaluation to determinate the influence of the employed processing conditions on microcracks, alpha-case layer, microstructure and hardness.
\end{abstract}

Manuscript received: March XX, 201X / Revised: August XX, 201X/Accepted: December XX, 201X

\section{Introduction}

Today, the aviation industry is facing a twofold challenge. On the one hand, the more and more demanding environmental concerns push the industry towards the decrease in fuel consumption and its associated emissions. This is being solved through the progressive adoption of lightweight concepts which make growing use of composites, high strength aluminum alloys and titanium. On the other hand, forecasts of not only market growth but the arrival of new players as well are pushing the industry to reconsider traditional production methods under cost-efficiency and agility premises.

Titanium and its alloys still represent the preferred option combining lightweight with high resistance at high temperatures and their choice is today frequent not only for the airframe but also for low temperature areas of the engine. Concerning their forming technologies, hydroforming, hot stamping and superplastic forming are recurrent ones. They all rely on very expensive and dedicated tooling which represents a severe drawback when facing common situations such as last-minute design modifications, production of spare parts (i.e. repair) or the smallest size batches.
Due to the ability to produce parts with no dedicated tooling, just through a numerically controlled tool which follows a programmed path, incremental sheet forming appears as a technology with the potential to decrease costs and gain agility when facing small series of sheet metal parts. ${ }^{1-3}$ For titanium applications, hot incremental sheet forming needs to be approached in most cases due to poor formability of this material at room temperature and high elastic recovery of the formed parts ${ }^{4}$. Among the existing process variants depending whether a support or not is used, Single Point Incremental Forming (SPIF), the one skipping any support and based on a single forming tool, seems the logic choice since the use of a support at medium-high temperatures would cut out agility and economic feasibility requested to hot forming technologies for prototyping, small size series or spare parts.

In order to hot form titanium by SPIF a key aspect is the heating system to be used, a topic already addressed by previous research both for titanium alloys and other difficult-to-deform materials. Work up to date can be classified in two main groups based on the heating concept developed.

The first group relates to the local heating of the sheet around the area to be deformed and has attracted a larger number of studies. 
Certainly, localized heating seems the logic option when the sheet is deformed locally. Both Duflou et al. ${ }^{5}$ and Göttmann et al. ${ }^{6}$ propose SPIF laser-based systems to form Ti-6Al-4V whereas works done by Fan et al. ${ }^{7}$, Ambrogio et al. ${ }^{8}$, Honarpisheh et al. ${ }^{9}$ or Najafabady et al. ${ }^{10}$ present for the same process variant and material concepts based on the Joule's effect instead. Some authors propose as well the combination of electrically-assisted heating and the Double Side Incremental Sheet Forming (DSISF) process variant. ${ }^{11-13}$ Usually, electrically-assisted forming makes use of the resistive heating generated in the tool-sheet interface to enhance material formability ${ }^{7}$. However, Asghar et al. ${ }^{12,13}$ use the phenomenon of electro-plasticity to deform a titanium alloy using high density DC pulses where the reduction in the flow stress is due to electron-dislocation interaction. Nevertheless, none of the works found consider the high levels of stresses induced on the sheet resulting of combined local mechanical and thermal loads. Geometric deviations of the formed parts are shown after unclamping for some cases ${ }^{10}$ but how to ensure that the geometry is kept after trimming the part has not been yet addressed by any of these solutions.

A second group of works including those from Ambrogio et al. ${ }^{14}$, Ji et al. ${ }^{15,16}$, Zhang et al. ${ }^{17,18}$, Khazaali et al. ${ }^{19}$ and Palumbo et al. ${ }^{20}$ have developed hot SPIF by heating the entire sheet, basically by means of a chamber equipped with heating elements around the clamping perimeter and/or inside the chamber cavity. Apparently less energy efficient, by this option lower temperatures, even for Ti-6Al-4V in Khazaali et al. ${ }^{19}$ and Palumbo et al. ${ }^{20}$ have been recorded. By heating the entire sheet, lower internal stresses and therefore lower geometric deviations when trimming the part should be expected, though no work provides results in this sense.

Geometric accuracy is another relevant aspect concerning hot forming by SPIF, in particular for titanium which shows springback issues even under tooling-based hot forming. Najafabady at al. ${ }^{10}$ report geometric accuracy data of Ti-6Al-4V parts achieved by their dynamically assisted local heating though parts are symmetrical and have not been trimmed. Palumbo et al. ${ }^{20}$ provide deviation profiles under different process conditions and temperatures for an asymmetric real geometry made of Ti-6Al-4V but also without accuracy data after trimming. Though not applied on hot formed titanium parts, most promising contributions in this sense refer to tool path correction based on machine learning predictions. Work done by Khan et al. ${ }^{21}$, Fiorentino et al. $^{22}$ and Zwierzycki et al. ${ }^{23}$ confirm all significant improvements in the accuracy.

Finally, works done by Fan et al. ${ }^{7}$, Ambrogio et al. ${ }^{8}$, Honarpisheh et al. ${ }^{9}$ and Khazaali et al. ${ }^{19}$ focus mainly on the relationship between process parameters and formability aiming to define adequate windows for Ti-6Al-4V forming. Work presented by Najafabady et al. ${ }^{10}$ also includes surface quality and hardness measurement results.

Therefore, the implementation of heating means, tool path correction algorithms and the identification of the process parameters effects are all required to hot form by SPIF titanium (and other materials with poor formability at room temperature) ensuring admissible formability and geometric accuracy.

In this sense, the present paper studies the heating cycles for heating up the sheet, forming and cooling down the part in a Ti-6Al$4 \mathrm{~V}$ hot SPIF operation based on the global heating of the sheet. The objective is to lead to the lowest geometric deviations. The unclamping and trimming conditions have been both considered. A post-forming material evaluation of the best obtained part in terms of accuracy has also been done to check the effect of the employed processing conditions on microcracks, alpha-case layer, microstructure and hardness.

\section{Experimental plan and set up}

A set of trials using $500 \times 500 \mathrm{~mm}^{2}$ Ti-6Al-4V sheets of $1.6 \mathrm{~mm}$ thick were made. These trials were performed, see Fig. 1, on an inhouse 5-axis gantry machine equipped with a furnace, a sheet clamping device and a housed head that protects it against temperature increase.

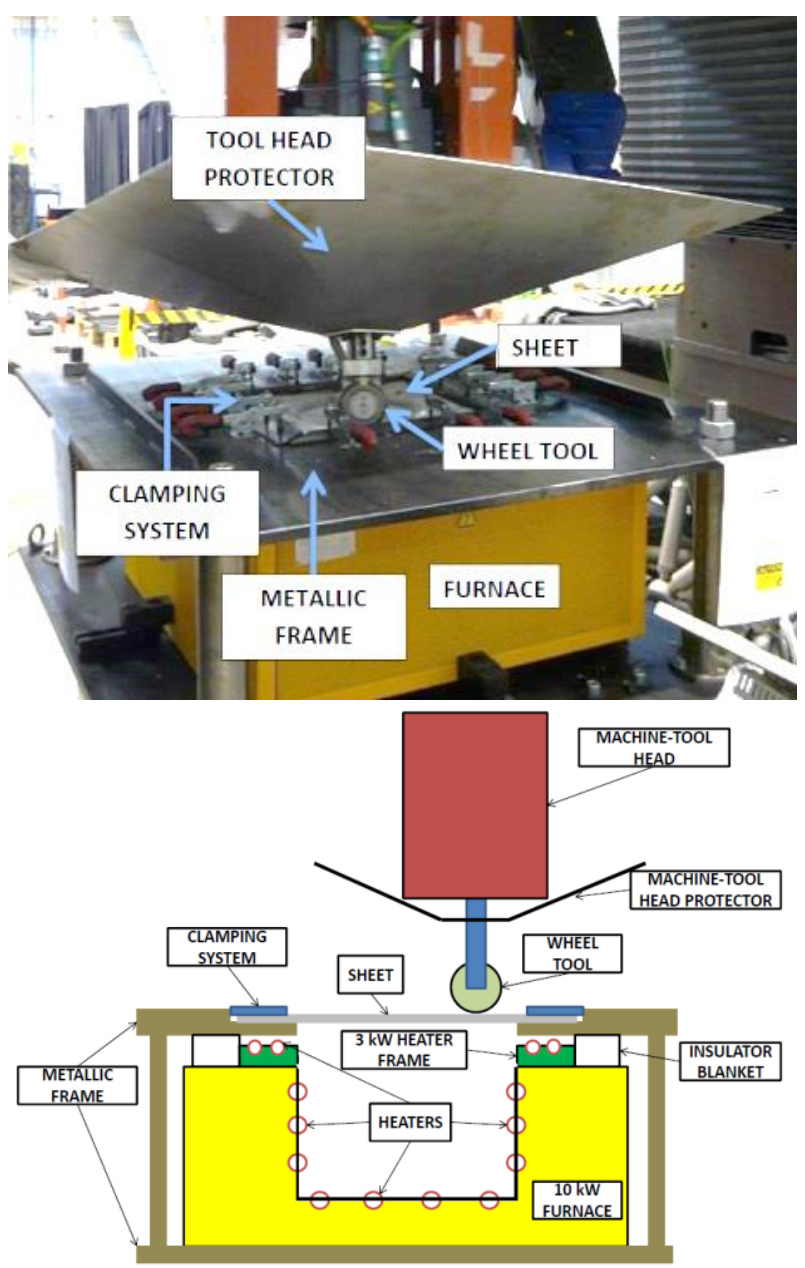

Fig. 1 Hot SPIF equipment used for the trials

When a conventional rigid punch tool is used adhesive wear plays a major role in the part surface. When sliding friction occurs at the toolsheet interface, the material can be scraped from the sheet and then adhered to the tool surface. ${ }^{24,25}$ This issue could be more relevant when using Titanium as material to deform, due to its ease to react with other metals, so in this case a ceramic wheel tool with a $11 \mathrm{~mm}$ forming radius and boron nitride as lubricant were chosen to provide adequate contact conditions during forming. The forming wheel was air cooled during forming. The furnace shows heaters both on the walls and the 


\section{ARTICLE TYPE}

bottom and holds a $10 \mathrm{~kW}$ power. The metal sheet to deform is put, supported on the metallic frame, on its top as a cover. Additionally, a cover with ceramic fiber blanket insulator can be laid over the sheet when no forming is performed and a controlled cooling is required. The clamping unit is also equipped with a frame of heaters which can provide up to $3 \mathrm{~kW}$ power to heat up the sheet perimeter covered by the clamping. The temperature at both the furnace and the clamping units is controlled by two independent thermocouples, placed one inside the furnace cavity and the other in a gap between the frame of heaters and the metallic frame respectively.

With the aim of studying the hot SPIF of Ti-6Al-4V to define the optimum temperature cycles leading to improve the geometric accuracy of the fabricated parts, three different types of trials were made: (i) heating trials aiming to identify an adequate heating up for the sheet, (ii) forming trials aiming to identify an adequate forming temperature and (iii) cooling trials aiming to identify an appropriate method to cool down the sheet after forming it.

\subsection{Trials for identifying the optimal heating procedure}

In order to identify the adequate heating method 4 different conditions, see Table 1, were tested. Sheets were heated up according to the trial conditions from room temperature up to $900{ }^{\circ} \mathrm{C}$ at the furnace and $500{ }^{\circ} \mathrm{C}$ at the clamp unit (temperature control points). These temperatures were selected because of being associated to power values close to the equipment limits. Previous tests had provided data about the time required to heat the sheet up to those temperatures. This information allowed to set heating times shown in Table 1 . The 4 trial conditions are graphically depicted in Fig. 2 where the furnace temperature evolution associated to each heating procedure is shown. Two iterations of each method were performed with the aim of evaluating the repeatability of results.

Table 1 Heating trial conditions

\begin{tabular}{ccc}
\hline PROCEDURE & $\begin{array}{c}\text { HEATING } \\
\text { MODE }\end{array}$ & $\begin{array}{c}\text { HEATING TIME } \\
{[\mathbf{h}]}\end{array}$ \\
\hline H1 & $150^{\circ} \mathrm{C}$ steps & 1 \\
H2 & $150^{\circ} \mathrm{C}$ steps & 2 \\
H3 & $50^{\circ} \mathrm{C}$ steps & 1 \\
H4 & $50^{\circ} \mathrm{C}$ steps & 2 \\
\hline
\end{tabular}

To carry out a temperature analysis, thermal recordings were obtained by means of a thermographic camera once the sheet temperature stabilized. The camera used to obtain all thermographic measurements was a XENICS ONCA-1380 whereas these data were analysed by means of the software Xeneth64. As Xu et al. ${ }^{26}$ did, the emissivity of the material was previously calibrated for different surface conditions. In this case, a trial consisting on heating up a previously deformed Ti-6Al-4V sheet (with Boron Nitride lubricant applied) at different furnace temperatures was carried out in order to obtain at the same time temperature readings with the thermographic camera and thermocouples at three different zones of the sheet (see Fig. 3 / 1- deformed zone, 2-flat zone at sheet center, 3-flat zone near a sheet edge). During the calibration trial one single emissivity value valid for the three zones was adjusted by the software for each furnace temperature. This value corresponds with the emissivity at which temperatures measured by thermographic camera matched well with those obtained by thermocouples. For furnace temperatures above $700^{\circ} \mathrm{C}$ the estimated emissivity for Ti-6Al-4V sheets with the lubricant applied was 0.885 , value used for all thermographic measurements performed in this work.

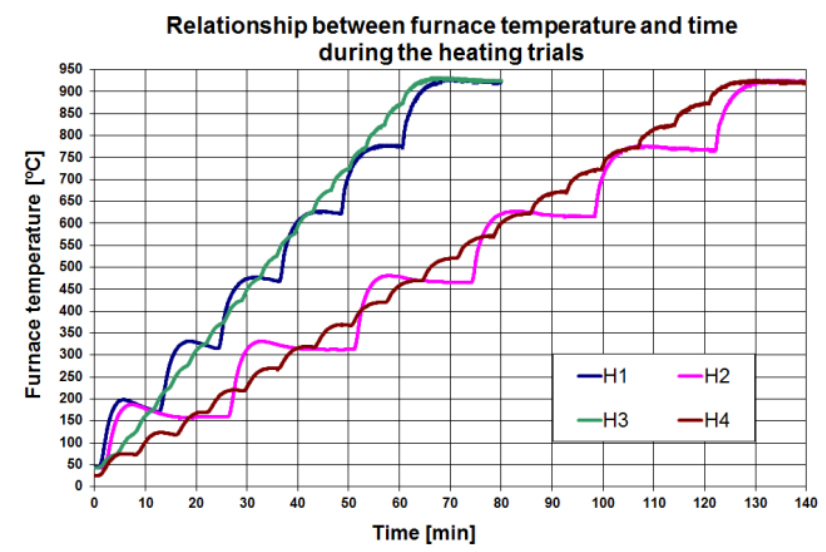

Fig. 2 Furnace temperature evolution during the heating trials

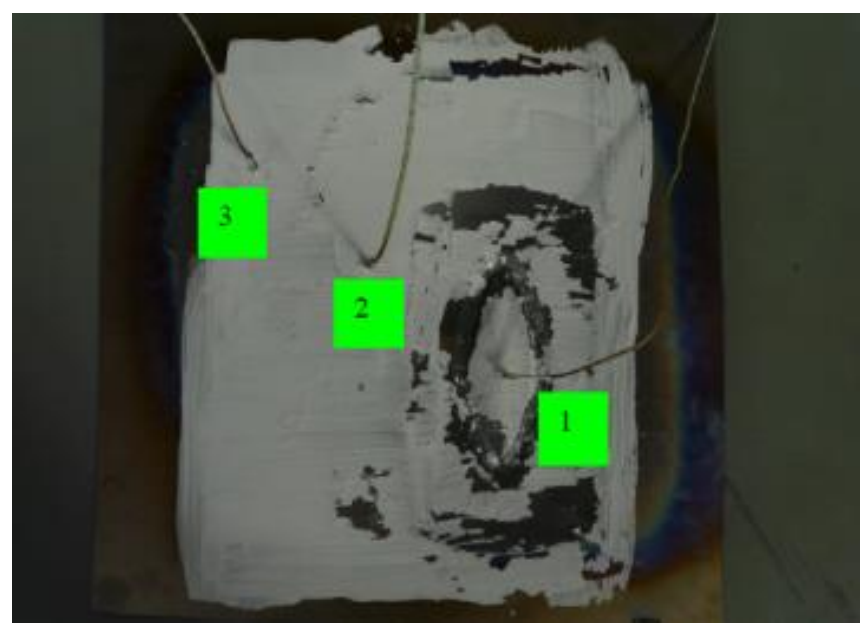

Fig. 3 Sheet coated with Boron Nitride for emissivity calibration trial

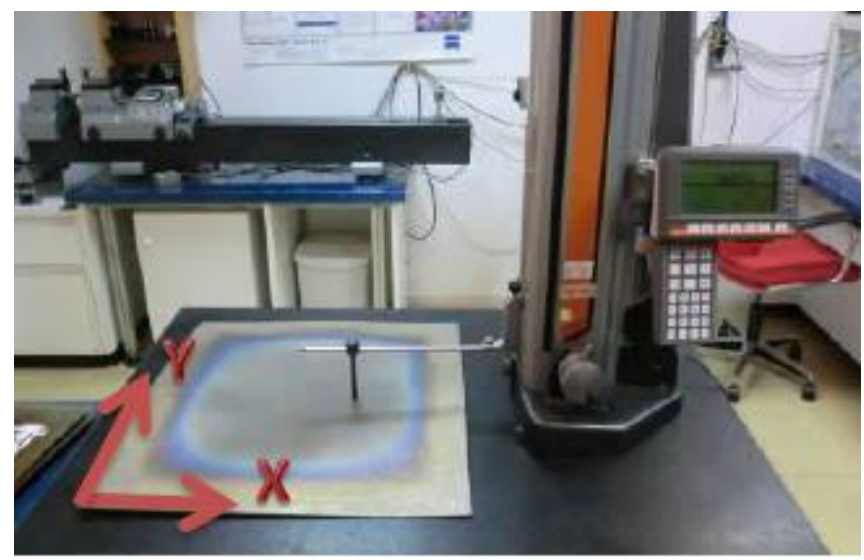

Fig. 4 Table of flatness to measure the non-deformed sheets 
After the heating, the sheet was unclamped without forming and was measured in a "table of flatness" to estimate the induced deviations on the sheet for each heating method. As Fig. 4 shows, to carry out this estimation the sheets were supported on the table and height measurements were done by means of a gauge in all intersections of $\mathrm{X}$, $\mathrm{Y}=50,100,200,250,300,400$ and $450 \mathrm{~mm}$.

\subsection{Trials to analyse the influence of the working temperature on the geometric accuracy}

For the forming trials, 4 different working temperatures were selected to analyse their influence on the material springback and as consequently on the final accuracy of the fabricated parts.

Table 2 shows the temperatures and the geometry designed. It represents a generic design with asymmetric features representative of aeronautic titanium sheet metal parts. The part has an upper perimeter of $280 \times 280 \mathrm{~mm}, 48.5 \mathrm{~mm}$ in height and three differentiated zones. The top one with a drastic wall angle variation zone from $15^{\circ}$ to $35^{\circ}$, the middle one with an almost constant wall angle $\left(35-38^{\circ}\right)$ and the bottom almost flat.

Table 2 SPIF trials temperature conditions and shape produced

\begin{tabular}{cc}
\hline Trial & Furnace $\mathbf{T}\left[{ }^{\circ} \mathbf{C}\right]$ \\
\hline T1 & 700 \\
T2 & 800 \\
T3 & 850 \\
T4 & 900 \\
\hline
\end{tabular}

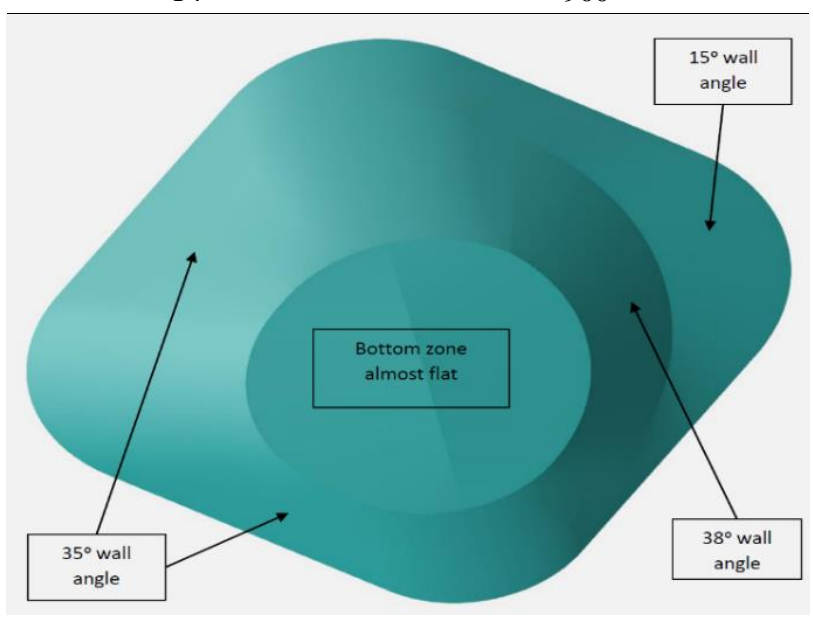

In all SPIF trials, parts were produced at a $1000 \mathrm{~mm} / \mathrm{min}$ feed rate and a $0.29 \mathrm{~mm}$ tool step down except in the bottom that a $0.5 \mathrm{~mm}$ tool step along the part surface was used. These parameters were defined taking into account the Ti-6Al-4V formability evaluation that previously had been carried out, ${ }^{27}$ since this study showed that the maximum material formability, that is, the maximum wall angle was obtained employing this parameters combination. The heating up of the sheets was made following conditions $\mathrm{H} 4$ according to Table 1, whereas the cooling of the parts consisted on switching off both the furnace and the heater frame after the forming stage without unclamping the parts until complete cooling down of the part.
To correlate the furnace temperature and the sheet temperature on the one hand and to analyse the sheet temperature homogeneity on the other one, in each SPIF trial temperature distributions of the upper face of the sheet were recorded with the thermographic camera before the forming, once the temperature stabilized. Moreover, during T3 and T4 trials temperature distributions of the sheets were also measured at the initial toolpath layer $(Z=0)$ and at the layer corresponding with a $Z=$ - $40 \mathrm{~mm}$ part depth. The thermal images were captured using the same equipment described in the previous subsection.

All the fabricated parts were measured using the optical 3D system ATOS COMPACT SCAN 5M of GOM and the obtained clouds of points were aligned for comparison with the original CAD by means of the GEOMAGIC CONTROL software. For the visualization of deviations after the alignment, the GOM INSPECT software was employed.

\subsection{Trials for identifying the optimal cooling procedure}

To analyse whether there is an influence of the cooling type on the geometric accuracy, two additional parts were fabricated according to heating up and forming conditions $\mathrm{H} 4$ and T4 respectively but using two different cooling procedures. These procedures consisted on:

1. $\mathrm{C} 1$ : free cooling by switching off both the furnace and heater frame after unclamping the sheet.

2. C2: controlled cooling without unclamping the sheet and according to stress relief conditions recommended by literature. ${ }^{4}$ To obtain optimal conditions regarding the stress relief, after the forming stage the part was covered with the thermally insulated cover.

For these trials 2 temperature control points were defined. One corresponds to the furnace temperature recording (located at the furnace cavity) and the other to the sheet center (upper face of the sheet). Temperature of this point was obtained either from thermal images obtained with the thermographic camera (cooling C1) or from a thermocouple passing through the sheet cover (cooling $\mathrm{C} 2$ ). Temperature evolution for both cooling procedures and control points can be seen in Fig. 5. The temperature evolution during $\mathrm{C} 1$ trial (unclamping the part just after forming) is considered the same as in T4 trial (no unclamping the part until complete cooling down) since, in both cases, the furnace and heater frame are switched off after the forming stage and no thermally insulated cover is employed as in C2 trial.

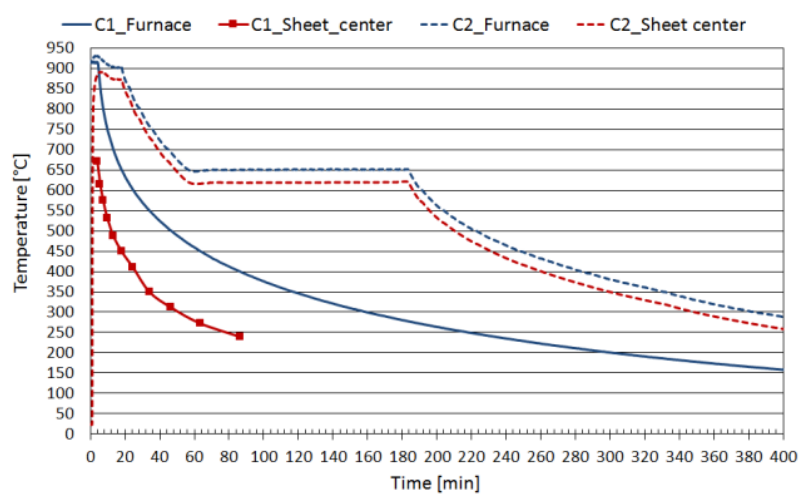

Fig. 5 Furnace and sheet temperatures during cooling trials $\mathrm{C} 1$ and $\mathrm{C} 2$ 
As in the previous subsection, the fabricated parts were measured in the optical 3D system and the obtained clouds of points were compared with the original CAD.

Furthermore, the parts fabricated with $\mathrm{C} 1$ and $\mathrm{C} 2$ cooling procedures were trimmed to extract a cross-shaped sample by means of a waterjet cutting machine with abrasive with the aim of performing an evaluation of the residual stresses accumulated on the parts once cooled and unclamped.

Finally, a metallographic analysis was performed in the $\mathrm{C} 2$ part, since it was the one obtained employing of the best heating, forming and cooling conditions previously analysed. Thus, five metallographic specimens were extracted as illustrated in Fig. 6 and another one was obtained from as-received (non-deformed) Ti-6Al-4V blank to carry out a post-forming material evaluation to investigate the influence of the temperature on microcracks, " $\alpha$-case" thickness, microstructure and hardness. Designation and location of the specimens are shown in Table 3. Location of the specimens (Ref $1-5$ ) was defined in order to analyse the influence of the different strain levels generated along the part associated to the different geometrical features depicted in Table 2.

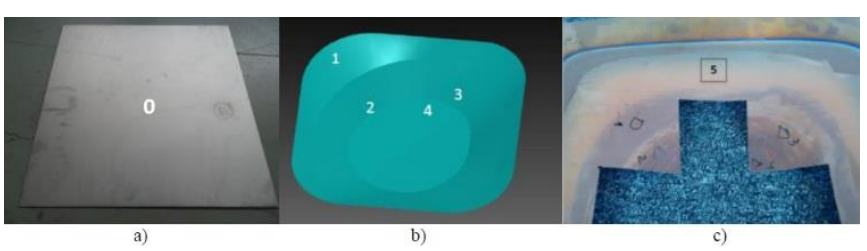

Fig. 6 Location of the specimens for metallographic analysis a) 0 position on the as-received Ti-6Al-4V blank, b) 1, 2, 3 and 4 positions located on the 3D CAD geometry and c) 1,2,3,4 and 5 positions on the $\mathrm{C} 2$ sample

Table 3 Table of specimen references and their associated conditions

\begin{tabular}{|c|c|}
\hline Ref & Condition \\
\hline 0 & As-received Ti-6Al-4V blank \\
\hline 1 & $\begin{array}{r}\text { Part C2 (heating H4, T4 forming, cooling C2). } \\
\text { Curved wall with } 15^{\circ} \text { angle. }\end{array}$ \\
\hline 2 & $\begin{array}{c}\text { Part C2 (heating H4, T4 forming, cooling C2). } \\
\text { Transition zone between the curved wall with 38 } \\
\text { angle and almost flat area. }\end{array}$ \\
\hline 3 & $\begin{array}{c}\text { Part C2 (heating H4, T4 forming, cooling C2) } \\
\text { Bottom edge of the sample with a 35-38 wall angle. }\end{array}$ \\
\hline 4 & $\begin{array}{c}\text { Part C2 (heating H4, T4 forming, cooling C2). } \\
\text { Almost flat bottom zone. }\end{array}$ \\
\hline 5 & $\begin{array}{c}\text { Part C2 (heating H4, T4 forming, cooling C2). } \\
\text { Area without any strain (zone out of the CAD } \\
\text { geometry with not tool contact). }\end{array}$ \\
\hline
\end{tabular}

Vickers hardness test were carried out on the core of the 6 references analysed through microscopic observation. These have been measured in two different sections ( $\mathrm{T}$ and $\mathrm{L}$ ) of each reference, being: - T: section perpendicular to the feed direction of the tool (values measured in this section are associated with the feed direction of the tool).

- $\mathrm{L}$ : section perpendicular to $\mathrm{T}$ and aligned with the direction of the feed of the tool.

Fig. 7 shows the positions of $\mathrm{T}$ and $\mathrm{L}$ sections of each one of the references, and the rolling direction of the sample, from which references 1 to 5 have been extracted, and reference 0 (as-received Ti6Al-V blank).

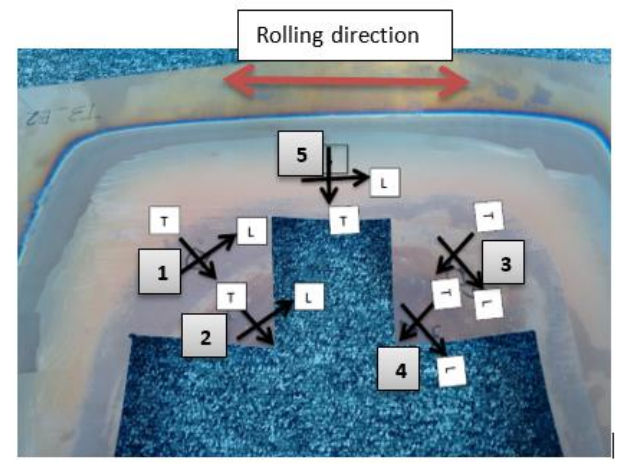

1 to 5 specimens extracted from the processed part

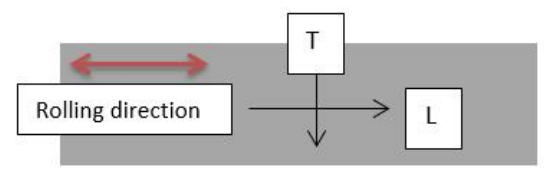

Specimen 0 extracted from as-received Ti-6Al-V blank

Fig. 7 Illustration of the positions of $\mathrm{T}$ and $\mathrm{L}$ sections

\section{Results and discussion}

\subsection{Optimal heating procedure}

The thermal images obtained during the heating trials were analysed to define an adequate heating up for the sheets. Due to the symmetry of the heated system, the area shown in Fig. 8 was defined as representative of the entire free working area $\left(400 \times 400 \mathrm{~mm}^{2}\right)$ which was not entirely captured and being the same in the four cases under analysis ( $\mathrm{H} 1, \mathrm{H} 2, \mathrm{H} 3$ and $\mathrm{H} 4)$. As it can be observed, the area consists of the triangular segment defined between the sheet center and two consecutive corners. From each thermographic area the representative temperature values shown in Table 4 were extracted. These values correspond with the mean values of each heating mode.

A quantitative analysis of the results extracted from Table 4 regarding the temperature distribution homogeneity points out that:

- Although the commanded temperatures were identical in all trials (900 ${ }^{\circ} \mathrm{C}$ at the furnace, $500{ }^{\circ} \mathrm{C}$ at the clamping) both maximal and minimal sheet temperatures were approximately $10-15^{\circ} \mathrm{C}$ higher by selecting $50{ }^{\circ} \mathrm{C}$ heating steps (trials $\mathrm{H} 3$ and $\mathrm{H} 4$ ) than by selecting $150{ }^{\circ} \mathrm{C}$ ones (trials $\mathrm{H} 1$ and $\mathrm{H} 2$ ). Hence, the gradual heating up allows the heating system formed by the furnace and the clamping to reach higher temperatures.

- Despite such difference at peak values, the Max - Min value is 
similar for all trials and the same trend is observed at the deviation. The significant temperature difference within the sheet is due to the temperature drop achieved along the sheet perimeter because of lower power of heaters over this area. This aspect makes the average temperature values of the entire sheet to decrease, not being a suitable indicator to define the percentage of points where a uniform temperature distribution is maintained. Therefore, as shown in Table 4, the mode of the temperature histograms, that is, the temperature value that more is repeated, of each method has been used to define this range, that is, mode $\pm 20^{\circ} \mathrm{C}$.

- Slightly higher temperatures achieved by $50{ }^{\circ} \mathrm{C}$ heating steps $(\mathrm{H} 3$, $\mathrm{H} 4)$ combined with deviations similar to those achieved by $150^{\circ} \mathrm{C}$ steps $(\mathrm{H} 1, \mathrm{H} 2)$ lead to lower temperature deviation in relative terms when using the lower steps, as reflected by the coefficient of variation. In any case, the absolute $50{ }^{\circ} \mathrm{C}$ temperature variation observed within the sheet in all cases could be relevant in terms of the Ti-6Al-4V plastic behaviour since its formability starts increasing drastically from $500{ }^{\circ} \mathrm{C}$ when the temperature is increased. ${ }^{27}$

- The percentage of temperatures within the mode $\pm 20^{\circ} \mathrm{C}$ is very similar (65\% approximately) in all trials and reflects very small differences in the temperature homogeneity despite heating up conditions. However, this percentage highlights that the entire geometry depicted in Table 2 would lie in the range where a uniform temperature distribution is maintained since the area to deform (approximately $280 \times 280 \mathrm{~mm}^{2}$ ) represents around $50 \%$ of the entire free working area $\left(400 \mathrm{x} 400 \mathrm{~mm}^{2}\right)$.

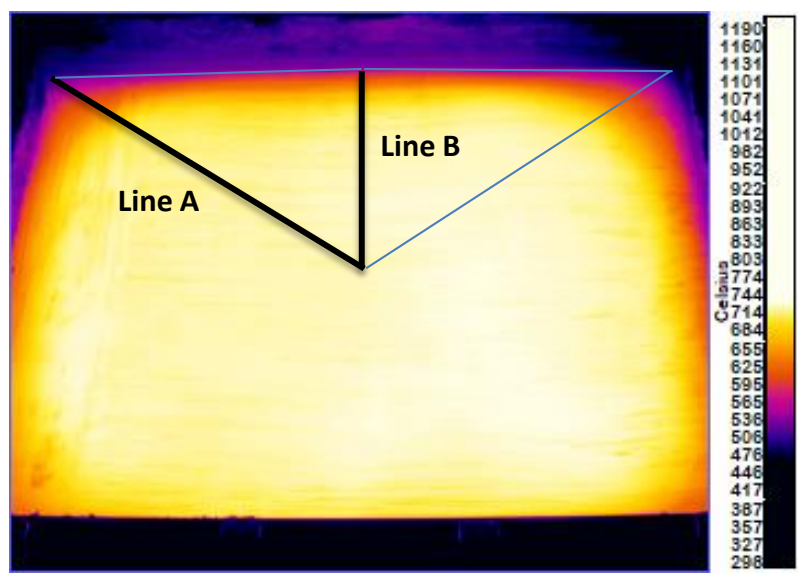

Fig. 8 Thermographic image of the sheet during one of the heating trials with the area and lines defined for the temperature analysis

Table 4 Representative temperature values for each heating procedure

\begin{tabular}{lcccc}
\hline Test & H1 & $\mathbf{H 2}$ & $\mathbf{H 3}$ & $\mathbf{H 4}$ \\
\hline Maximum $\left[{ }^{\circ} \mathbf{C}\right.$ ] & 725 & 727 & 731 & 736 \\
Minimum [ ${ }^{\circ} \mathbf{C}$ ] & 478 & 477 & 485 & 494 \\
Max-Min $\left[{ }^{\circ} \mathbf{C}\right.$ ] & 247 & 250 & 246 & 242 \\
Average, $\mathbf{x}\left[{ }^{\circ} \mathbf{C}\right.$ ] & 685 & 686 & 691 & 696 \\
Standard deviation, s $\left[{ }^{\circ} \mathbf{C}\right.$ ] & 52 & 53.9 & 51.3 & 49.1 \\
Coefficient of variation, s/x [\%] & 7.6 & 7.9 & 7.4 & 7.1 \\
Mode $\pm \mathbf{2 0}{ }^{\circ} \mathbf{C}[\%]$ & 65.3 & 64.3 & 65.5 & 65.6 \\
\hline
\end{tabular}

The temperature distribution within the sheet was also analysed along lines A and B shown in Fig. 8. Graphs in Fig. 9 showing the extracted lines point out that:

- All lines show two clearly differentiated zones. The first one shows a temperature increase as a result of the transition between the colder sheet perimeter area influenced by the clamping heaters and the rest of clamping elements and the central area influenced by furnace heaters. In the second zone the temperature features a steady evolution since it corresponds to the central area only influenced by the furnace.

- The temperature increase along the first zone is slower for lines A due to the corner effect produced because of the square geometry of the sheet and the higher heat losses at this zone as typically occurs in the induction heating of large titanium slabs or carbon steel RCS billets. ${ }^{28}$ Hence, in lines A the temperature needs 80 $100 \mathrm{~mm}$ to reach the steady zone whereas in lines B it is reached just after $35-40 \mathrm{~mm}$.

- The steady temperature reached in the second zone is identical for both lines $\mathrm{A}$ and $\mathrm{B}$, being in all cases quite homogeneous, with variations below $10^{\circ} \mathrm{C}$.

- The heating method seems to have a slight influence on the temperature slope in the first zone. Thus, trials made using $50{ }^{\circ} \mathrm{C}$ heating steps $(\mathrm{H} 3, \mathrm{H} 4)$ reach the steady zone earlier than those made using $150{ }^{\circ} \mathrm{C}$ steps $(\mathrm{H} 1, \mathrm{H} 2)$, in particular for lines A, where the steady temperature can be reached up to $20 \mathrm{~mm}$ earlier. This behaviour is in concordance with the values of coefficient of variation shown in Table 4 which point out an improvement on the temperature distribution homogeneity when using $50{ }^{\circ} \mathrm{C}$ heating steps and more specifically the $\mathrm{H} 4$ procedure.
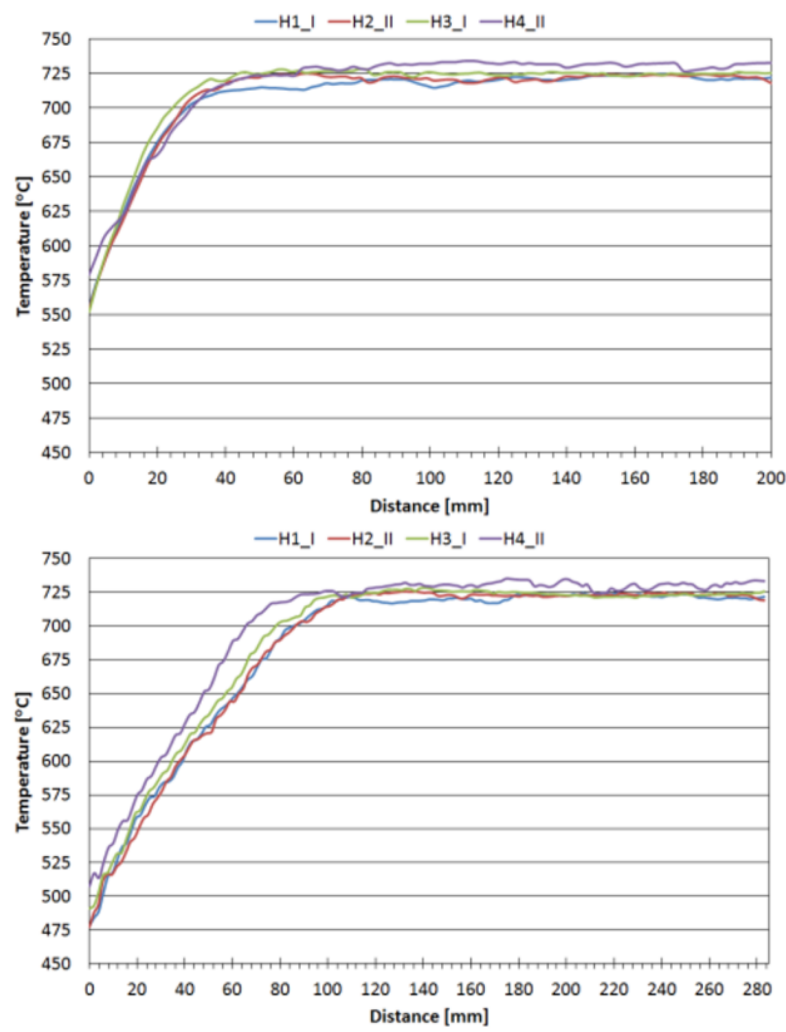

Fig. 9 Temperature distribution of lines B (above) and line A (below) once temperature is stabilized in trials $\mathrm{H} 1, \mathrm{H} 2, \mathrm{H} 3$ and $\mathrm{H} 4$ 


\section{ARTICLE TYPE}

The heating up of a clamped sheet introduces internal stresses that can lead to undesired deformations when the sheet is unclamped. Based on the hypothesis that these stresses might be different depending on the selected heating method applied the geometrical deviations of blanks after being heated up and then cooled down (with no mechanical deformation applied) were analysed.

Height measurements described in previous section were plotted into deviation maps, as illustrated in Fig. 10, and their representative values were extracted from them. Table 5 shows the obtained values. As mentioned in the previous section, measurements were only taken over the sheet surface laying within the clamping, but they are referred to those points over the entire surface having direct contact with the measurement table (height $=0$ ).

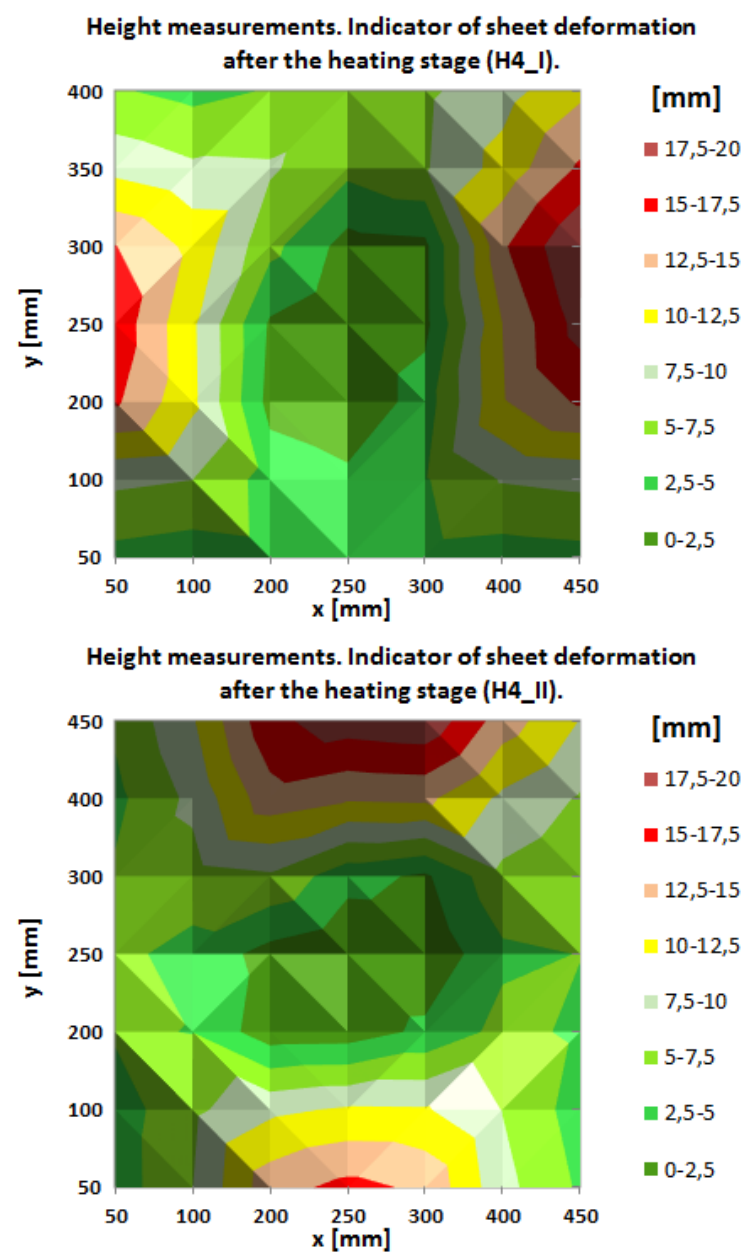

Fig. 10 Geometric deviations maps for H4_I and H4_II heating trials

Table 5 Mean deviation values of each heating procedure

\begin{tabular}{lcccc}
\hline Procedure & H1 & H2 & H3 & H4 \\
\hline Maximum [mm] & 21.3 & 22.2 & 20.6 & 19.7 \\
Average, $\mathbf{x}[\mathrm{mm}]$ & 14.7 & 14.1 & 11.4 & 7.6 \\
\hline
\end{tabular}

From these values it can be observed that despite the maximum heights and deviations do not differ much among trials, the mean deviation shows a clear improvement when using $50{ }^{\circ} \mathrm{C}$ heating steps combined with the $2 \mathrm{~h}$ heating (trial $\mathrm{H} 4$ ) which is aligned with the results observed from the thermal images. In this case (see Fig. 10), most of deviations maintain below $7.5 \mathrm{~mm}$ except in areas adjacent to the central zone of two facing edges of the sheet where the deviations increase up to values around $20 \mathrm{~mm}$. The maps corresponding to the two heating $\mathrm{H} 4$ trials show the same pattern but with a $90^{\circ}$ rotation. Whereas in H4_I trial the maximum deviations are found in edges aligned with the $\mathrm{Y}$ axis ( $\mathrm{X}=50$ and $450 \mathrm{~mm}$ ), in H4_II trial the maximum deviations are observed in the other two edges $(\mathrm{Y}=50$ and $450 \mathrm{~mm}$ ). This behaviour could be related to the sheet clamping stage before the heating, since none specific procedure was followed to control the order in what the four edges of the sheet were clamped from one trial to other. The influence of this aspect should be studied in depth in the future.

The results are confirmed by plotting the cumulative histograms of the sheets deviation, see Fig. 11, where it can be observed that the amount of points showing the lowest deformations is clearly higher under $\mathrm{H} 4$ trials condition. Thus, around a $75 \%$ of the points show deviations within $0-10 \mathrm{~mm}$ for this trial whereas for the other ones is below $20 \%$.

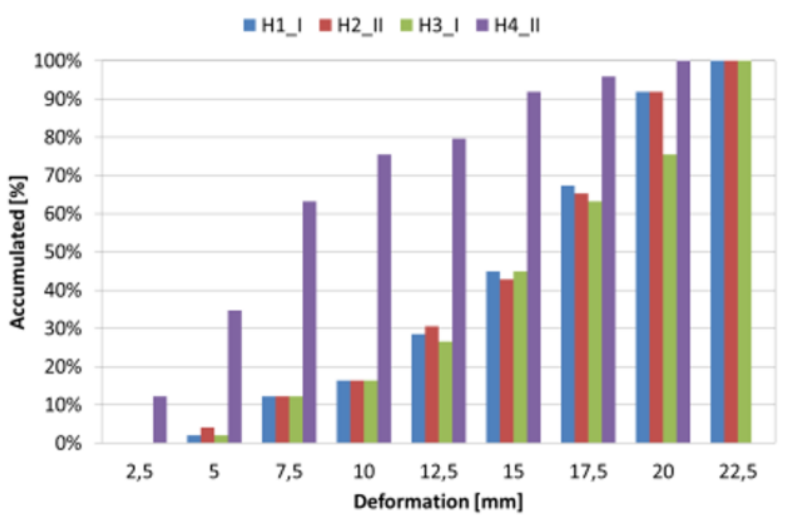

Fig. 11 Cumulative deviation histograms of the sheets after heating trials of $\mathrm{H} 1, \mathrm{H} 2, \mathrm{H} 3$ and $\mathrm{H} 4$

\subsection{Influence of the working temperature on the geometric accuracy}

Fig. 12 shows the temperature histograms and their associated representative temperature values for each SPIF trial of the same triangular area defined in previous section before just forming starts.

The histograms show that, in all cases, the largest percentage of temperatures is found around the peak value that corresponds with the more homogeneous temperature distribution of the sheet center. However, as Fig. 9 showed, the sheet suffers an abrupt drop of temperature due to the cooling effect of clamping system. The results indicate that as the working temperature increases this effect is more relevant due to the limited power of the heater frame that is not able to supply enough heat to the edges of the sheet, thus increasing the differences between the temperatures of the sheet center and edges. As 
the histograms show, these differences are found around $60-70{ }^{\circ} \mathrm{C}$ in $\mathrm{T} 1$ (furnace at $700{ }^{\circ} \mathrm{C}$ ) whereas in $\mathrm{T} 2$ (furnace at $800^{\circ} \mathrm{C}$ ) and $\mathrm{T} 3$ (furnace at $850^{\circ} \mathrm{C}$ ), which have a similar distribution, the differences increase to $130-140{ }^{\circ} \mathrm{C}$ and in $\mathrm{T} 4$ (furnace at $900{ }^{\circ} \mathrm{C}$ ) to $200-210^{\circ} \mathrm{C}$. The highest peak value and the narrowest distribution of its histogram, highlight that the more homogeneous temperature distribution is obtained in $\mathrm{T} 1$, that is, with the lowest temperature value at the furnace. The increase of the coefficient of variation of temperature and the drop on the percentage of points in the range peak value $\pm 20^{\circ} \mathrm{C}$ (see Fig. 12 ), confirms also the decrease on the homogeneity of temperature distribution as the working temperature increases.

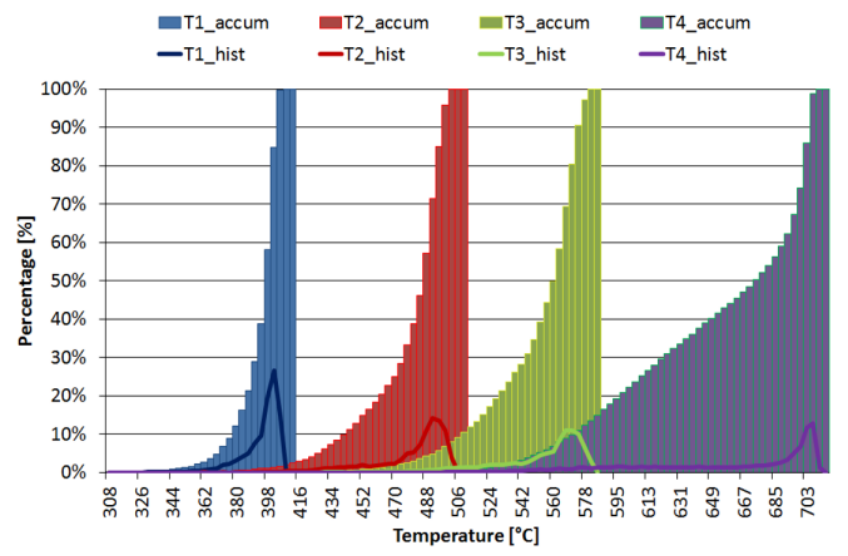

\begin{tabular}{lcccc}
\hline Test & T1 & T2 & T3 & T4 \\
\hline Max $\left[{ }^{\circ} \mathbf{C}\right]$ & 413 & 510 & 586 & 711 \\
Average, $\mathbf{x}\left[{ }^{\circ} \mathbf{C}\right]$ & 396 & 480 & 553 & 664 \\
Deviation, s $\left[{ }^{\circ} \mathbf{C}\right]$ & 11.7 & 23.6 & 27.7 & 50.4 \\
Coefficient of variation, s/x [\%] & 2.9 & 4.9 & 5.0 & 7.6 \\
Mode $\pm \mathbf{2 0}{ }^{\circ} \mathbf{C}[\%]$ & 87.8 & 77.2 & 71.7 & 60.5
\end{tabular}

Fig. 12 Temperature histograms and representative values for each SPIF trial

Fig. 13 shows the relation between the furnace temperature and the sheet top face average temperature associated to each trial. As it was expected, as the furnace temperature increases the sheet temperature also increases. However, in the analysed range there is not a linear relation between the both temperatures. In fact, this relation of temperatures can be described by means of a third-order polynomial. This tendency points out that the heating rate of the sheet is accelerated considerably from $500{ }^{\circ} \mathrm{C}$ approximately when increasing the furnace temperature. This evolution of the sheet temperature could be associated to rapid microstructural changes that Ti-6Al-4V features above $500{ }^{\circ} \mathrm{C}$ associated to dynamic recovery or continuous and discontinuous dynamic recrystallization. Furthermore, the titanium surface is embrittled by oxygen above $540{ }^{\circ} \mathrm{C}$ as a function of time and temperature. ${ }^{4}$ These temperature results match well with the material behaviour observed by Ortiz et al. ${ }^{27}$ where it was concluded that the formability of Ti-6Al-4V starts enhancing drastically from $500{ }^{\circ} \mathrm{C}$ approximately.

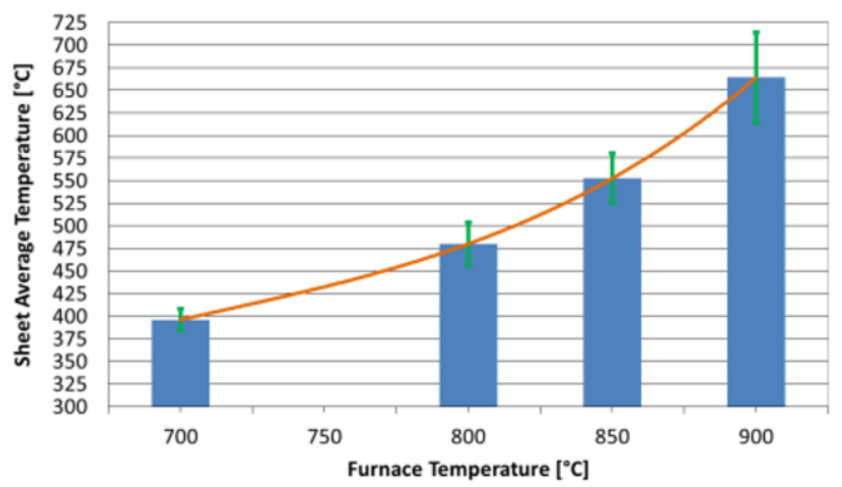

Fig. 13 Furnace-sheet temperature relation

In spite of having the more homogenous temperature distribution, $\mathrm{T} 1$ trial finished before obtaining the final part since the sheet broke during the forming at the final stage. As we observe above, the temperatures reached on the sheet in this case are not high enough to enhance the material formability as the study of Ortiz et al. ${ }^{27}$ points out. In fact, in $\mathrm{T} 1$ temperature is around $400^{\circ} \mathrm{C}$ so the formability is similar to that obtained at room temperature. Thus, the maximum wall angle of the target part is higher than the admissible wall angle that can be formed at this temperature that according to Ortiz et al. ${ }^{27}$ is lower than $40^{\circ}$. In the rest of trials, the temperature was high enough to enhance the material formability and the parts were fabricated safely. However, it can be said that $\mathrm{T} 2$ temperature conditions are in the limit to fabricate the part successfully since the temperatures are found on the range where the formability of Ti- $6 \mathrm{Al}-4 \mathrm{~V}$ starts increasing. The change on tendency around these temperature values in the relation between the furnace and sheet temperatures depicted in Fig. 13 suggested a microstructural change of the material. Therefore, taking into account this aspect the temperature analysis during forming has been focused on $\mathrm{T} 3$ and $\mathrm{T} 4$ trials.

For the analysis of the temperature evolution during forming, two lines have been extracted from the selected areas. The lines position within the part is exactly the same than that selected for analysing the heating trials, see Fig. 8. Line A represents the temperature distribution of a section containing a corner of the part whilst line $\mathrm{B}$ represents the temperature distribution of a section containing a flat wall. As Fig. 14 shows the results at $Z=0$ point out that the entire part lies in the range where a uniform temperature distribution is maintained (temperature in a range of $20^{\circ} \mathrm{C}$ in $\mathrm{T} 3$ and in a range of $10^{\circ} \mathrm{C}$ in $\mathrm{T} 4$ approximately). The value of this range increases in $\mathrm{T} 3$ since in this case the application of the lubricant over the sheet was not so uniform as in $\mathrm{T} 4$, thus, introducing a source of noise on the temperature readings with drastic temperature variations between adjacent areas containing different amount of lubricant.

Anyway, though in $\mathrm{Z}=-40 \mathrm{~mm}$ temperature differences between the corner and the flat wall along the deformed zones (1-1' versus 2-2' in Fig. 14) are observed, the most relevant aspect is that the results suggest that the temperature on the stretch to deform by the tool ( 1 '-3 and 2 '-3 in Fig. 14) in each moment maintains in a uniform range during all forming stage (a range of $20^{\circ} \mathrm{C}$ for both cases). Both in $\mathrm{T} 3$ and T4 there is a sudden drop of temperature near point 3 due to the influence of the cooling air of the tool. In the deformed zones the 
temperature is higher along the flat wall (2-2') than along the corner zone (1-1') since this area is closer to the heaters of the furnace.
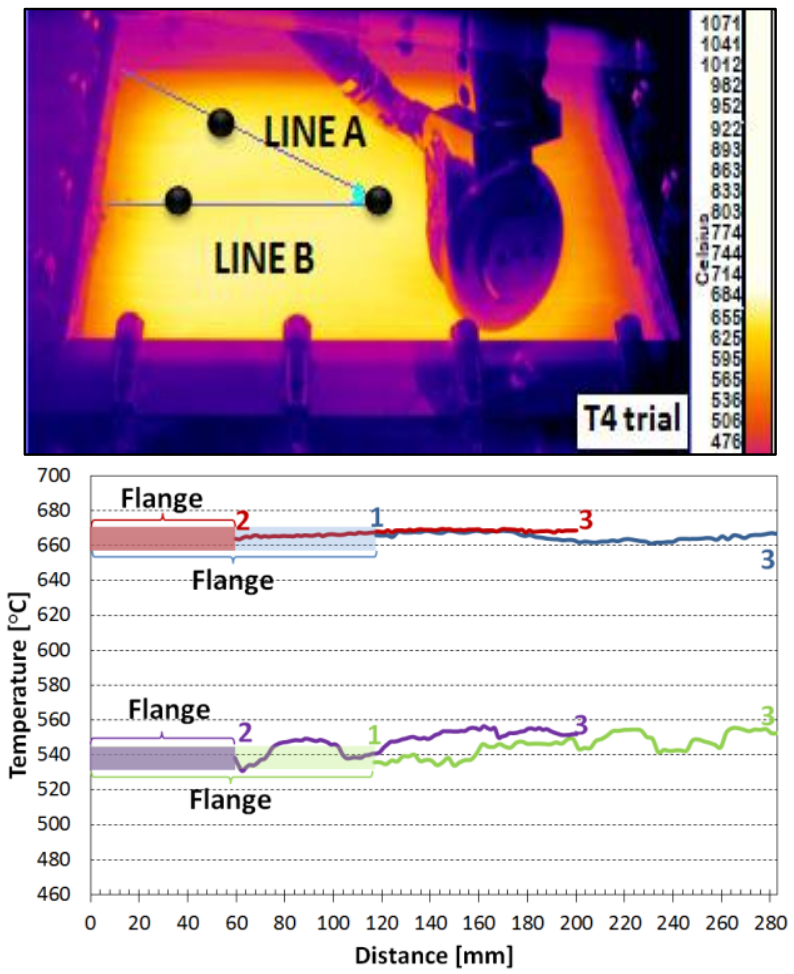

a)
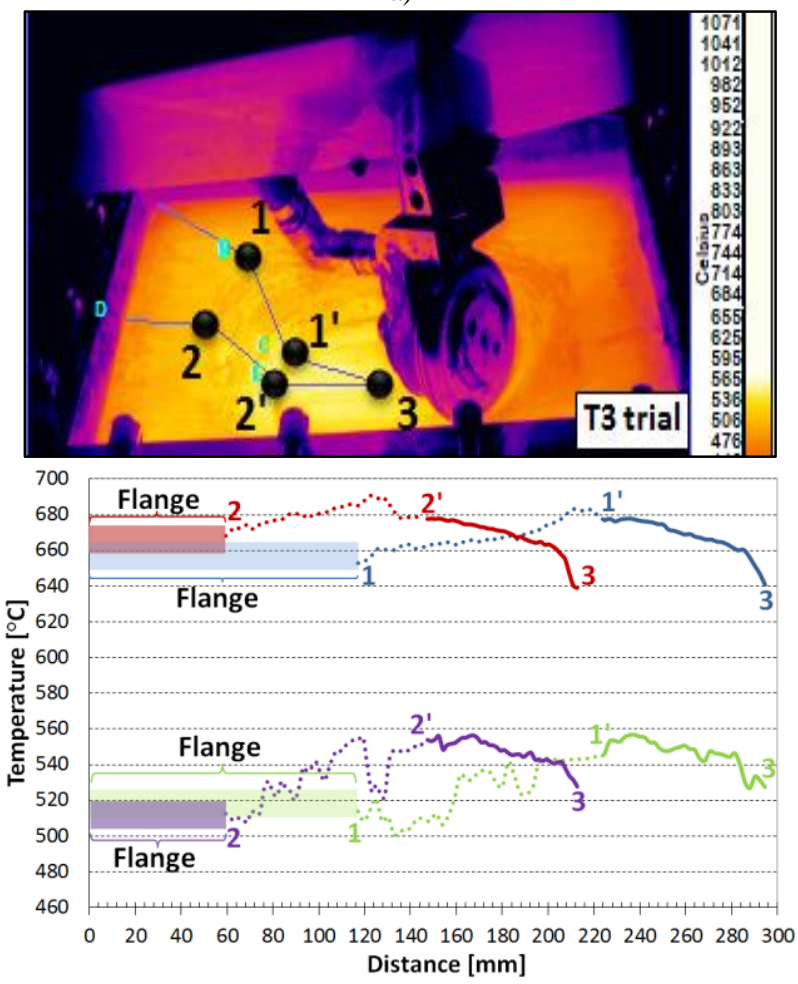

b)

Fig. 14 Temperature distribution of A and B lines during T3 (in green and purple) and T4 (in blue and red) trials at a) $\mathrm{Z}=0$ and b) $\mathrm{Z}=-40 \mathrm{~mm}$
Table 6 shows representative deviation values of each part extracted from the maps of deviations depicted in Fig. 15.

Table 6 Deviation results of SPIF trials at different temperatures

\begin{tabular}{cccccc}
\hline Trial & $\begin{array}{c}\text { Max }+ \\
{[\mathbf{m m}]}\end{array}$ & $\begin{array}{c}\text { Max }- \\
{[\mathbf{m m}]}\end{array}$ & $\begin{array}{c}\text { Average }+ \\
{[\mathbf{m m}]}\end{array}$ & $\begin{array}{c}\text { Average }- \\
{[\mathbf{m m}]}\end{array}$ & $\begin{array}{c}\mathbf{\pm 1} \mathbf{~ m m} \\
{[\mathbf{\%}]}\end{array}$ \\
\hline T2 & 5.38 & -12.96 & 1.75 & -2.95 & 25.3 \\
T3 & 4.70 & -13.52 & 1.47 & -2.67 & 27.5 \\
T4 & 4.27 & -11.10 & 1.45 & -3.16 & 29.7 \\
\hline
\end{tabular}

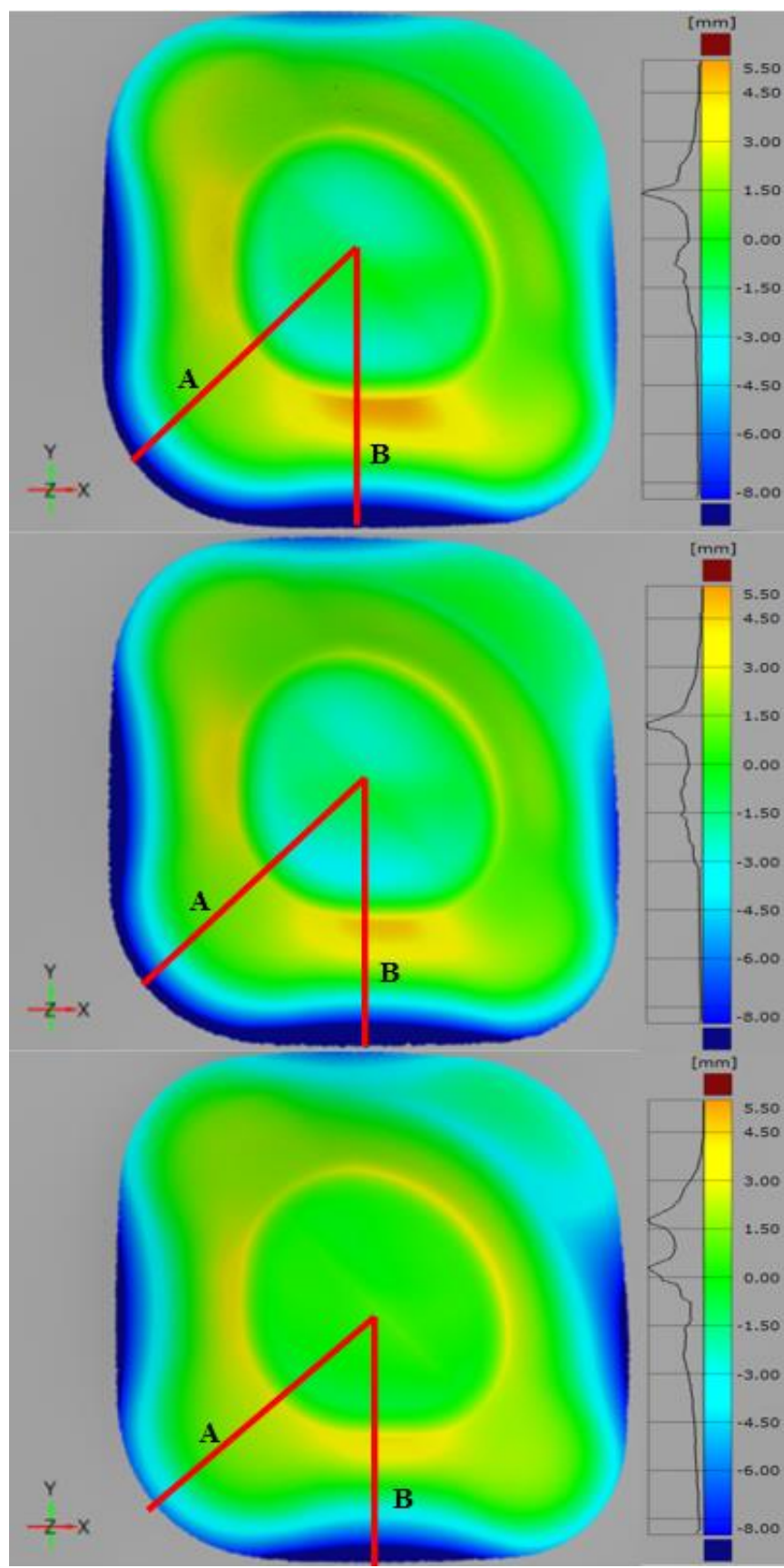

Fig. 15 Colour map of deviations for T2 (above), T3 (middle) and T4 (below) trials.

From the obtained results it can be said that all parts share the same deviation pattern. All parts suffer an initial negative overforming 
deviation that is mainly related to the bending effect around the perimeter area since during these trials the working area was $400 \times 400$ $\mathrm{mm}^{2}$ whereas the part features a perimeter of $280 \times 280 \mathrm{~mm}^{2}$. By increasing temperature, positive underforming deviations at the flat areas decrease due to the reducing effect of temperature on material springback. This reduction of springback effect is clearly observed in Fig. 16 (image above, B section in Fig. 15) where deviation of each part regarding the target geometry along the section of a flat wall is depicted. The elastic recovery (springback) in the flat wall is considerably minimized in $\mathrm{T} 4$, as highlight the decrease of underforming and the flatter profile of the part. Taking into account temperature values of Fig. 14, Young modulus of elasticity (see Fig. 17) is found around $70 \mathrm{GPa}$ for the entire part in $\mathrm{T} 3$ whereas in $\mathrm{T} 4$ this value decreases down to $25 \mathrm{Gpa}$ approximately. Therefore, as occurs in the work performed by Khazaali and Fereshteh-Saniee, ${ }^{19}$ the springback is reduced since the drastic flow stress reduction at higher temperatures ${ }^{27}$ overcomes the Young's modulus diminution that, as it is known, would increase the springback. Fig. 16 also shows (image below, A section in Fig. 15) that springback is not so critical aspect in the corners due to the rigidity of these zones in comparison with walls and consequently all parts share almost the same behaviour along them.
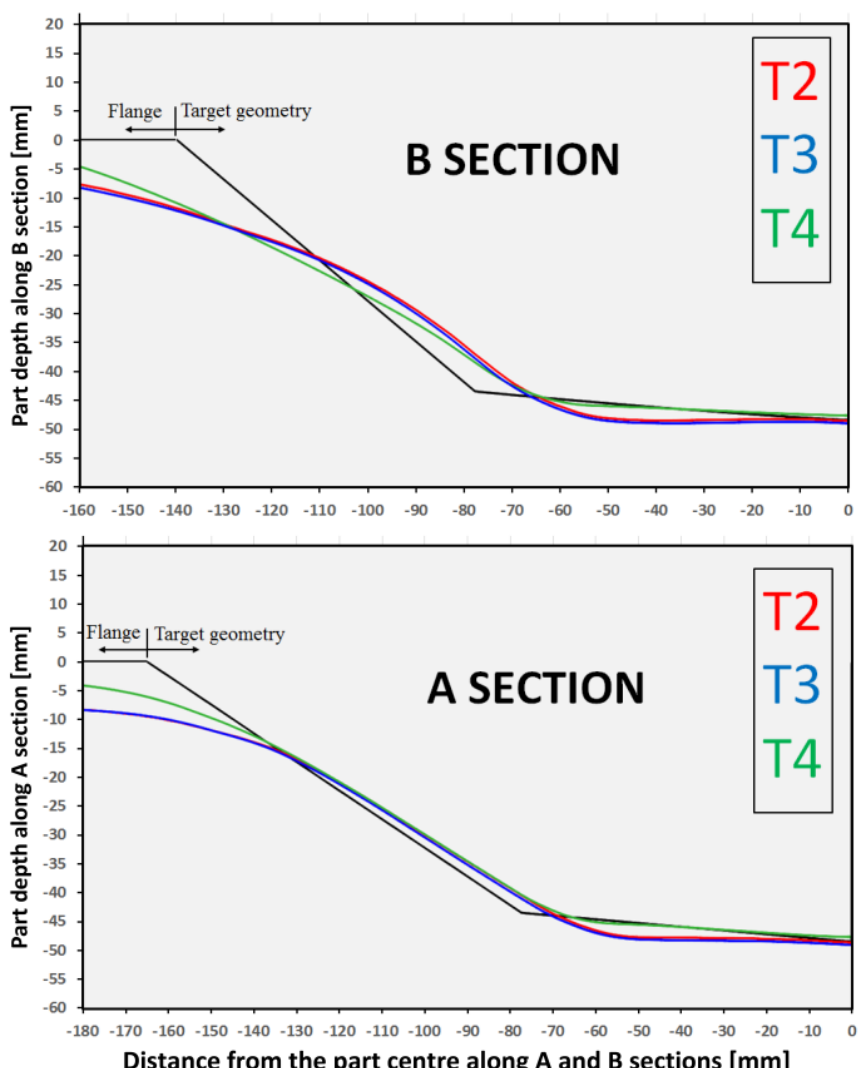

Fig. 16 Deviations along a flat wall (above, B section) and a corner (below, A section) of the part extracted from deviation maps of Fig. 15

Regarding T2 part, taking into account its temperature values represented in Fig. 12 and considering that temperature is maintained around the same values along the area to deform in each instant as in T3 and T4 (see Fig. 14), its associated Young modulus of elasticity is found around $85 \mathrm{GPa}$, a value quite similar to that of T3 though slightly higher. The opposite occurs with the flow stress reduction that for T2 temperature condition is slightly lower than for $\mathrm{T} 3$ temperature condition. ${ }^{27}$ Thus, the combined influence of these two parameters (Young modulus and flow stress) over the springback is similar in both cases and for this reason the deviation profiles of $\mathrm{T} 2$ and $\mathrm{T} 3$ are so similar.

Temperature increase leads also to better results at the bottom area with lower deviation values and less variation on the results.

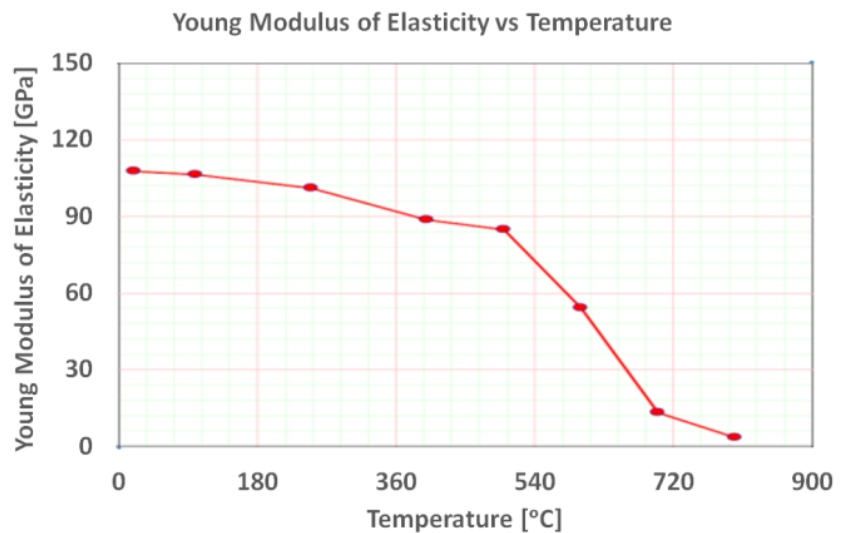

Fig. 17 Young Modulus of Elasticity for Ti-6Al-4V at temperatures of $20,100,250,400,500,600,700$ and $800^{\circ} \mathrm{C}^{27}$

Moreover, the higher the temperature, the lower the deviation around the perimeter of the part at the flat walls and their corner intersection. On the contrary, at the area with lower wall angle at the top of the part, the temperature increase seems to increase overforming. Thus, on balance, temperature increase lead to higher deviations at the part perimeter area. This is mainly due to the higher the temperature the higher the plastic strain and consequently the higher the unwanted bending of the sheet around the perimeter using the system proposed that does not feature a backing plate for the part.

In general, the maps representative deviation values point out that within the analysed range a temperature increase has an overall positive effect since the positive underforming deviations that are mainly related to the springback effect decrease. The percentage of deviations in the range of $\pm 1 \mathrm{~mm}$ is an indicator of it and as Table 6 shows, the best results were obtained in $\mathrm{T} 4$ trial, that is, with $900{ }^{\circ} \mathrm{C}$ at the furnace $\left(665 \pm 50^{\circ} \mathrm{C}\right.$ on the sheet). On the other hand, excessive negative overforming deviations, mainly related to the bending effect around the perimeter area, are unavoidable despite of increasing temperature and significantly minimize the percentage of deviations in the range of \pm 1 $\mathrm{mm}$.

\subsection{Optimal cooling procedure}

The cooling procedure is expected to decrease residual stresses induced by both thermal and mechanical means so that differences in the part geometry before and after the part is unclamped and trimmed are minimised. In order to analyse the effect of cooling deviation maps of parts produced were also analysed. Maps associated to each of the cooling procedures are shown in Fig. 18 and representative values extracted from these maps can be found in Table 7. Test T4 where no specific cooling was applied (heaters switched off after forming, part unclamped when cooled) was taken as a reference and its results are 

ARTICLE TYPE

also included. In this sense, the results of $\mathrm{C} 1$ trial are used to analyse the effect of unclamping the sheet just after the forming stage whereas the results of $\mathrm{C} 2$ trial serve to analyse the effect of applying a controlled cooling with an intermediate stress relief treatment.

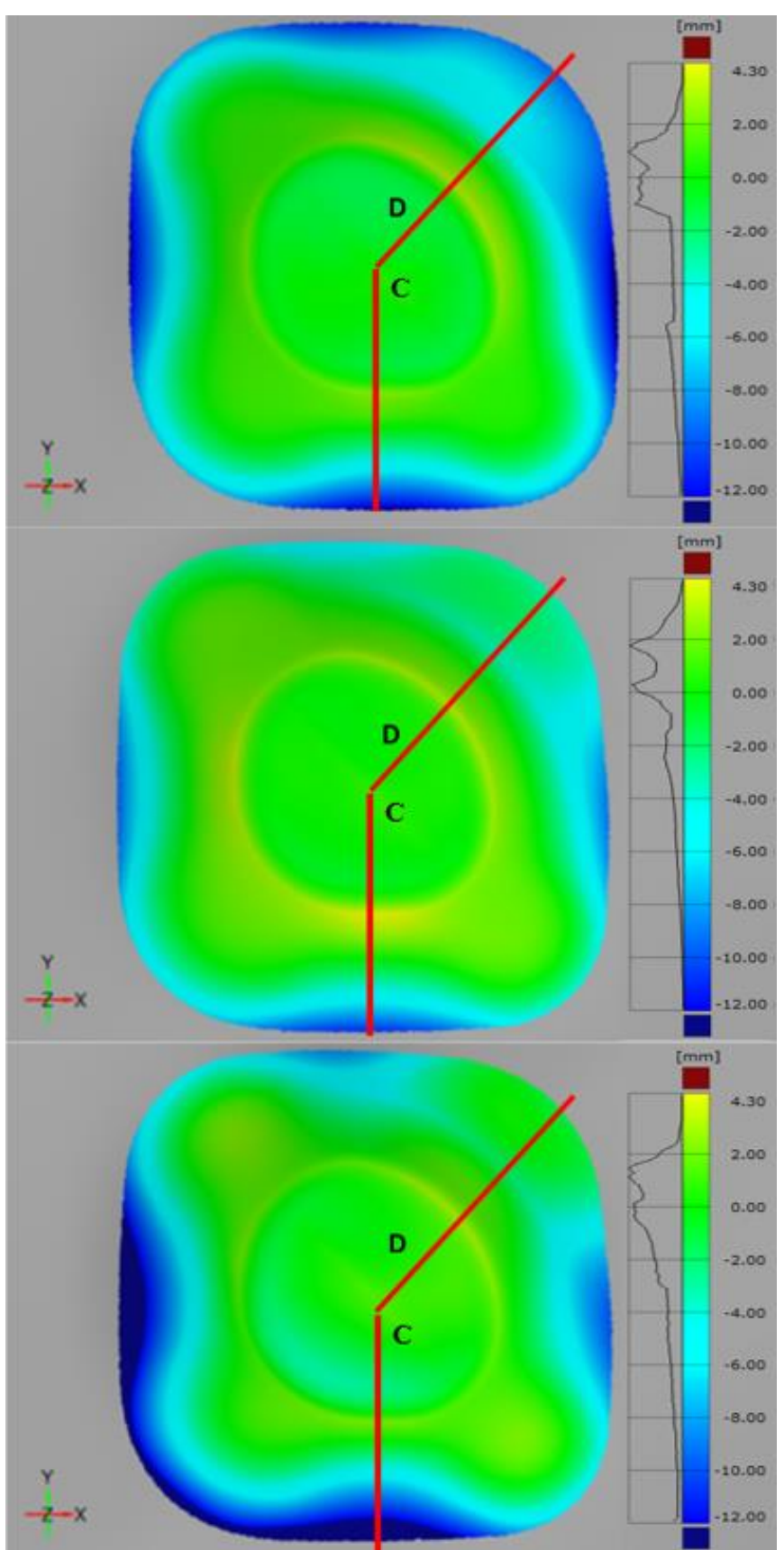

Fig. 18 Colour map of deviations for C1 (above), T4 (middle) and C2 (below) trials

Table 7 Results of cooling procedures

\begin{tabular}{llllll}
\hline Trial & $\begin{array}{l}\text { Max+ } \\
{[\mathbf{m m}]}\end{array}$ & $\begin{array}{l}\text { Aver+ } \\
{[\mathbf{m m}]}\end{array}$ & $\begin{array}{l}\text { Max- } \\
{[\mathbf{m m}]}\end{array}$ & $\begin{array}{l}\text { Aver- } \\
{[\mathbf{m m}]}\end{array}$ & $\begin{array}{l}\mathbf{\pm 1 m m} \\
{[\mathbf{\%}]}\end{array}$ \\
\hline C1 & 3.42 & 1.06 & -13.26 & -3.82 & 37.3 \\
T4 & 4.27 & 1.45 & -11.10 & -3.16 & 29.7 \\
C2 & 3.24 & 1.09 & -16.06 & -4.16 & 30.3 \\
\hline
\end{tabular}

As in the previous subsection, negative overforming deviations, mainly related to the bending effect around the perimeter area, are excessive in all cases. The part has an upper perimeter of $280 \times 280$ $\mathrm{mm}^{2}$ whereas the entire free working area is $400 \times 400 \mathrm{~mm}^{2}$. Thus, the free area of the sheet which does not belong to the target geometry ( 60 $\mathrm{mm}$ in length from each side of the part to the clamping zone) represents a relevant source of error in terms of the obtained geometry and at the same time it is considered a disturbance element in the analysis of results as it is explained below. To overcome this issue in the future, the presence of a backing plate is necessary to reduce to the maximum this free area affected by the bending.

In any case, a preliminary quantitative analysis of the deviations maps represented in Fig. 18 points out that:

- In $\mathrm{C} 1$ though positive underforming deviations are slightly reduced, basically at the bottom of part walls, negative overforming deviations around the entire perimeter of the part increase with respect to $\mathrm{T} 4$ trial. This aspect indicates that, as the temperature evolution on the part can be considered the same in both cases, the unclamping moment of the part (before or after the cooling down) is a factor to consider since influences the final accuracy.

- In $\mathrm{C} 2$, as in the previous case, positive underforming deviations are slightly reduced at the bottom of the part walls. Regarding the negative overforming deviations along the perimeter of the part, two different behaviours are observed. Thus, in the zones with higher wall angle values these deviations increase considerably whereas in the zone with lower wall angle, overforming deviations decrease slightly.

Considering the results of Table 7 it could be concluded that, in principle, $\mathrm{C} 1$ is the best cooling procedure since in this case the percentage of deviations within the range of $\pm 1 \mathrm{~mm}$ is the highest. However, these results are completely affected by the lack of a backing plate and a deeper analysis of the deviation maps suggests something different. In this sense, the application of $\mathrm{C} 2$ cooling could have a positive effect on the elimination of mechanical stresses accumulated on the clamping system due to the stress relief treatment on the one hand, and avoiding the part distortion associated to an abrupt cooling on the other hand. Thus, the part is not distorted so much as in T4 and C1 trials during the cooling stage and after changing boundary conditions, that is, after being unclamped.

Firstly, Fig. 19 suggest that, though negative overforming deviations are higher, $\mathrm{C} 2$ part maintains more accurately the shape obtained just after forming operation as the following aspects point out:

- The target geometry in this section is a flat wall and the depicted wall features a flatter profile in the case of $\mathrm{C} 2$ trial whereas in $\mathrm{T} 4$ and $\mathrm{C} 1$ trials the same wall shows a slight curvature related to an elastic recovery during cooling stage.

- In the 3 cases the obtained walls are almost parallel. However, the characteristics of the sheet edge (left zone of the image) differs from case to case. Unlike in $\mathrm{C} 1$ and $\mathrm{T} 4$ trials, $\mathrm{C} 2$ trial conditions lead to a quite horizontal sheet edge. This combination of 
geometrical features indicates that a sharper edge is defined at the top of the wall in $\mathrm{C} 2$ part (Duflou et al. ${ }^{5}$ explained that a sharper edge of this zone of the part suggested a systematic reduction of springback and unwanted plastic deformation due to the use of elevated temperatures, taking as reference 3D part measurements without unclamping the sheet). This means that the stress relief treatment performed in $\mathrm{C} 2$ is beneficial to minimize mechanical stresses accumulated on the clamping system whereas in T4 and C1 these stresses are not eliminated. Thus, the part at this zone shrinks after unclamping or during the non-controlled cooling and consequently negative overforming deviations are minimized.

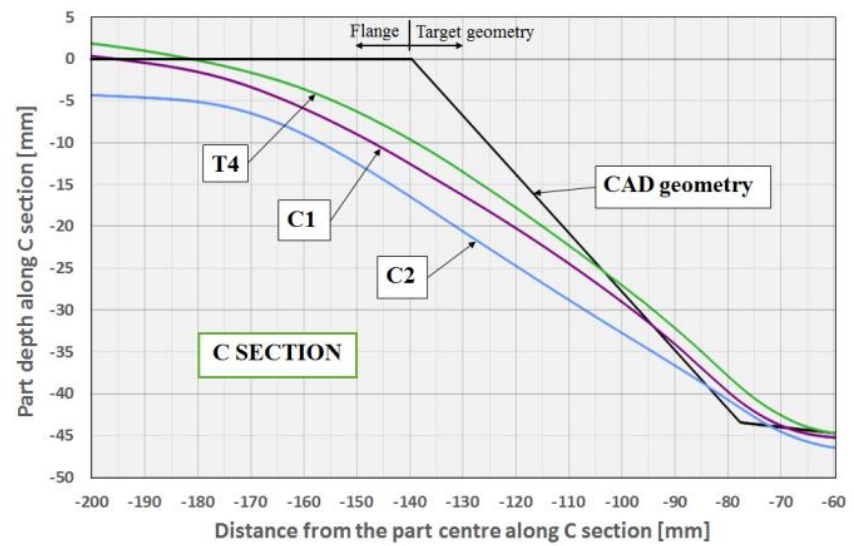

Fig. 19 Shape profiles of a flat wall of high angle (C section) extracted from the deviation maps of Fig. 18

Secondly, as mentioned before, the high negative overforming deviations in the perimeter of the part are generated to a large extend due the lack of a backing plate and the resulting bending of the sheet around the mentioned zone, generating unwanted plastic deformations at the sheet edges not belonging to the target geometry. However, the map of $\mathrm{C} 2$ also reveals that whereas this effect is very relevant at the flat walls and the zones with abrupt wall angle changes, the zone with low wall angle $\left(15^{\circ}\right)$ is very close to the target geometry (see Fig. 20) pointing out that the effect of bending at this zone is significantly lower. This could be related to the lower forces employed to deform this area that are not high enough to generate high plastic deformations of the material in the sheet edge surrounding the mentioned area unlike what happens in sheet edges surrounding zones with high wall angles where the higher forces employed produce higher plastic deformations over a more extensive area. On the contrary, as Fig. 20 also shows, the accuracy of $\mathrm{T} 4$ part and especially of $\mathrm{C} 1$ part in this zone is lower. Assumed that, as explained above, $\mathrm{C} 2$ part maintains more accurately the shape obtained just after forming operation due to the applied stress relied treatment during cooling stage (part distortion associated to the cooling stage is minimized), in T4 and C1 the part at this zone spread, thus increasing the overforming due to the non-controlled cooling and the stress relief just after unclamping the part. However, there are significative differences between deviations obtained with $\mathrm{T} 4$ or $\mathrm{C} 1$, highlighting the influence of the unclamping moment of the part (before or after the cooling down). This issue should be studied more in deep in the future.

Therefore, it could be concluded that the proposed cooling procedure, $\mathrm{C} 2$, is beneficial to reduce the global springback of the part, defined by Jeswiet et al., ${ }^{29}$ that occurs after the final unloading and dismounting from the clamps.

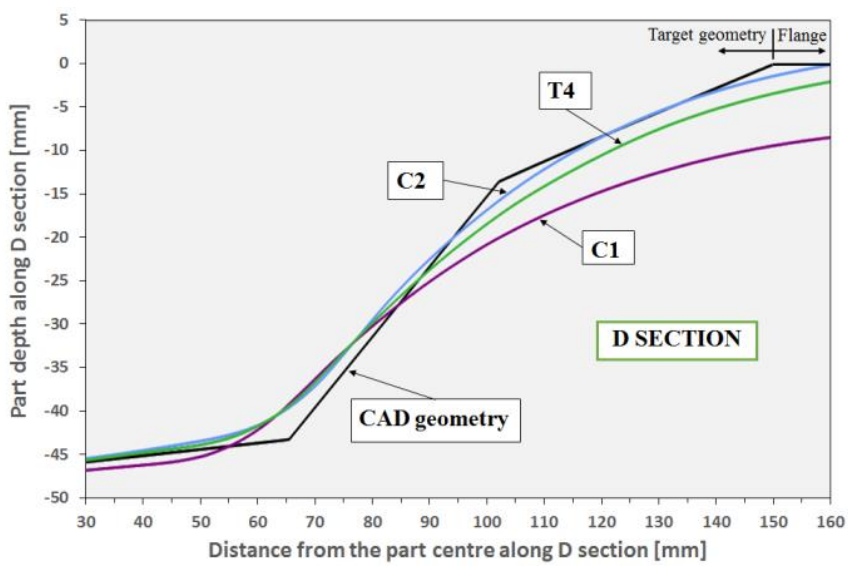

Fig. 20 Shape profiles of a wall with low $\left(15^{\circ}\right)$ and high $\left(38^{\circ}\right)$ angle (D section) extracted from the deviation maps of Fig. 18

On the other hand, final residual stresses accumulated on the parts once unclamped can be considered almost identical for both parts, $\mathrm{C} 1$ and C2, as Fig. 21 shows.

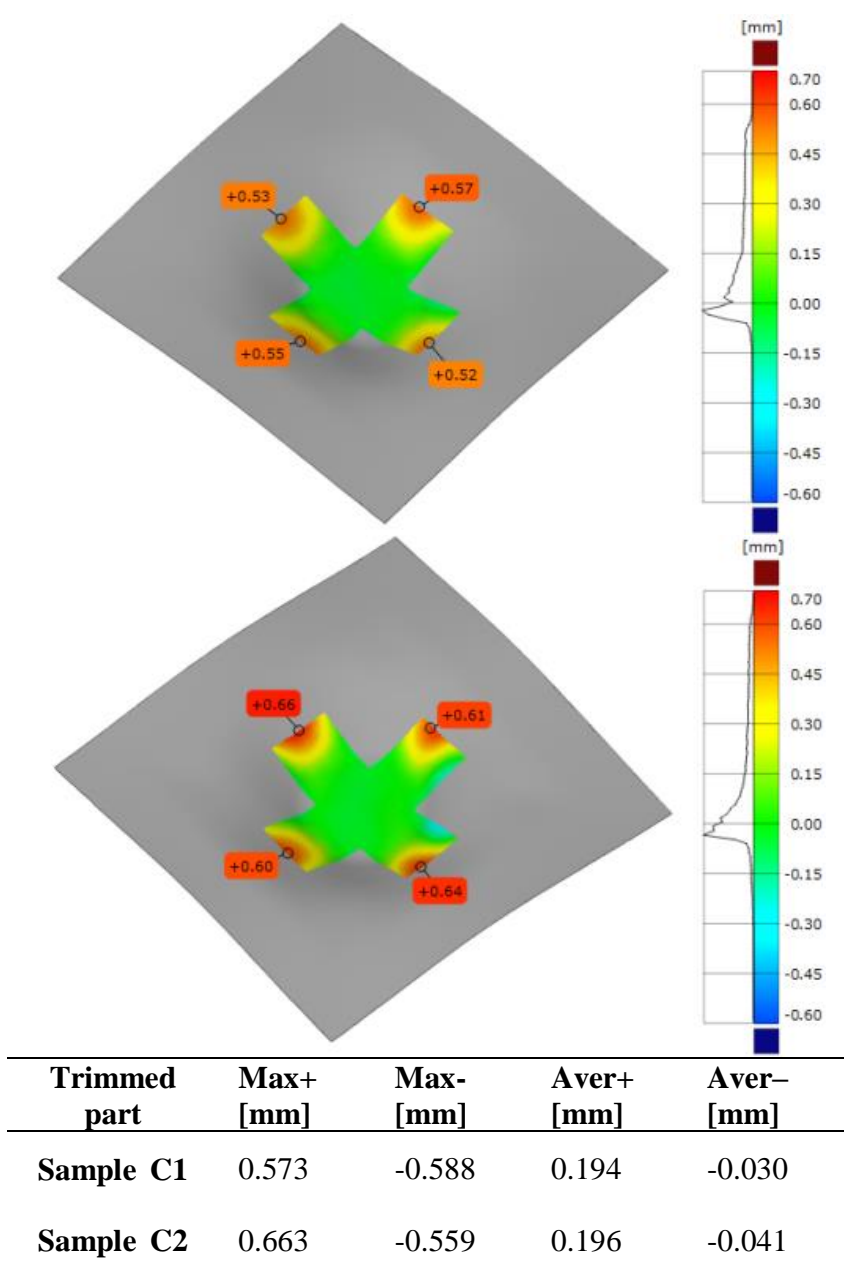

Fig. 21 Map of deviation and table of results of the cross-shape sample / Fit between the sample and C1 part (above) and C2 part (below)

In fact, the two samples trimmed show an identical deviation pattern 


\section{ARTICLE TYPE}

with respect to their reference part. In general, the deviations after trimming can be considered very low since the maximum values are bounded to zones close to the trimming path and highlight the effectiveness of the high process temperatures to minimize residual stresses along the shaped area and consequently to eliminate the third kind of springback defined by Jeswiet et al. ${ }^{29}$ that it is usually generated after trimming.

\subsection{Post-forming material evaluation}

The material characterization has been performed to investigate the influence of the temperature on microcracks, " $\alpha$-case" thickness, microstructure and hardness. In the previous section, the sample $\mathrm{C} 2$ has been considered as the one with optimal working temperature results and along this section, a metallurgical analysis on this sample will be presented.

\subsubsection{Microcracks and alpha-case}

The microcracks and the $\alpha$-case have been analysed on both surfaces (inner and outer) of each specimen, considering:

- Inner surface: surface in contact with the tool.

- Outer surface: the surface facing the furnace.

Table 8 shows the optical micrographs of the studied specimens corresponding to the zones next to both inner and outer surfaces of the sheet. This table also shows the thickness values of " $\alpha$-case" in each evaluation zone on the specimen.

The micrographs show that the absence of microcracks is generalized for all the areas observed. These results, compared to studies developed by Ortiz et al., ${ }^{27}$ show that reducing the wall angle the presence of microcracks is also decreased due to the lower strain suffered. The geometry of referenced research work showed an angle of the specimen wall of $55^{\circ}$ constant and in the present work have a maximum wall angle of $38^{\circ}$. Thus, microcracks were observed in specimens within the part deformation area and on both sheet surfaces. ${ }^{27}$ Their absence from the non-deformed bottom area of the part suggested that they result from failure of the alpha-case layer affected brittle material under the action of the forming tool. Examined specimens also revealed that microcracks did not extend over the alpha-case layer.

Regarding the "a-case" layer, based on the microscopic observation and measurement, there are not significant differences among the values of the specimens corresponding to deformed areas (Ref. 1 to Ref. 4) of the part. In fact, as Fig. 14 showed, the difference of temperatures between an upper (point 1) and bottom (point 1') zone of the part during the forming (representative zones of the $1-4$ specimens location) are not significant $\left(20-25^{\circ} \mathrm{C}\right)$. The " $\alpha$-case" in Ref. 5 is lower since it corresponds to a zone out of the CAD geometry and close to the clamping system where the temperature decreases considerably as Fig. 9 pointed out. Furthermore, in all cases the values in both faces, inner and outer, are very similar due to the employed cooling procedure (C2) leading to a drastic minimization of the temperature gradient between inner face and outer face of the part as

Fig. 5 showed (C2 vs $\mathrm{C} 1)$.

Table 8 Optical micrograph of the Ti- $6 \mathrm{Al}-4 \mathrm{~V}$ specimens and their $\alpha$ case thickness evolution. a) Inner surface and b) Outer surface

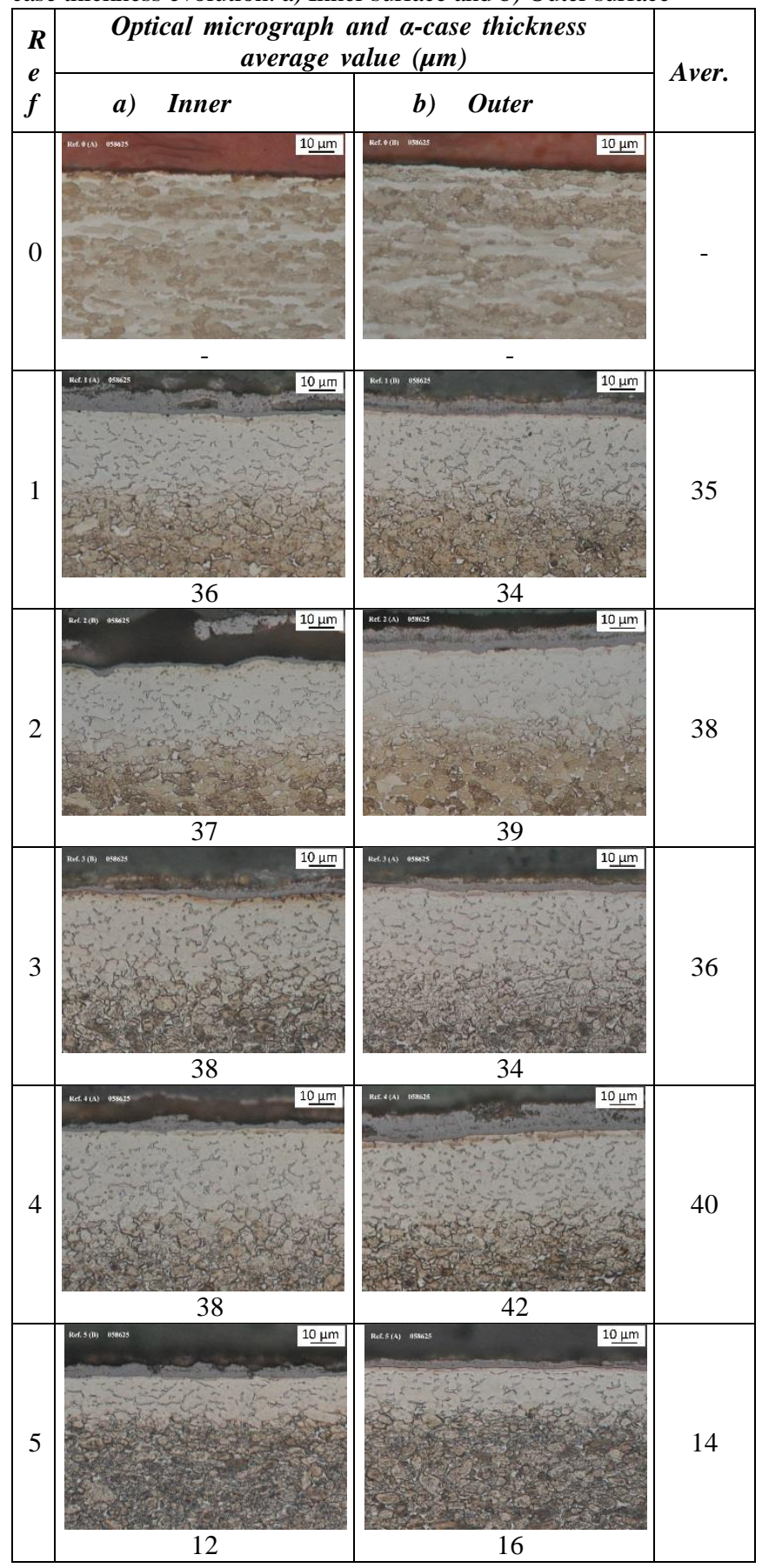

\subsubsection{Microstructure}

As Fig. 22 shows, in all references, the microstructure consists of elongated grains of alpha (white) and intergranular beta (gray).

The areas with different strain level, as well as the ones that reached varied process temperatures, did not show significantly different grain shapes. Concerning to the strain level, Ref. 3 shows the highest one, 
while Ref. 1 and Ref. 4 are opposed to it due to the low wall angle and an almost flat area respectively. The references 2 and 4 are positioned on the deepest locations of the sample, closer to the furnace heaters, and due to this they suffered the highest temperature levels. Ref. 5, extracted nearby the clamping zone (no strain zone) and where the temperature level achieved is the lowest, shows an equiaxial microstructure which reaffirms the results achieved by Ortiz et al. ${ }^{27}$

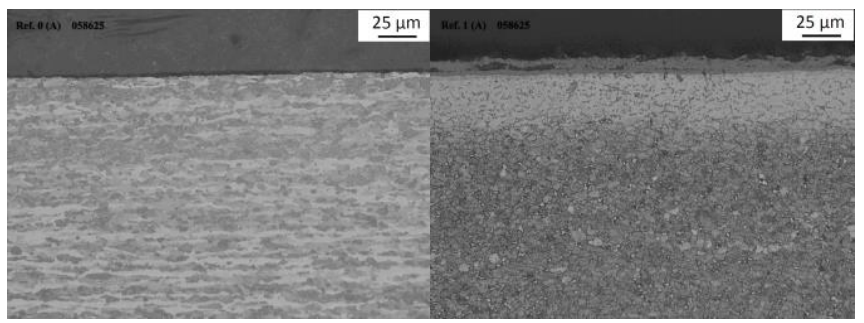

a)

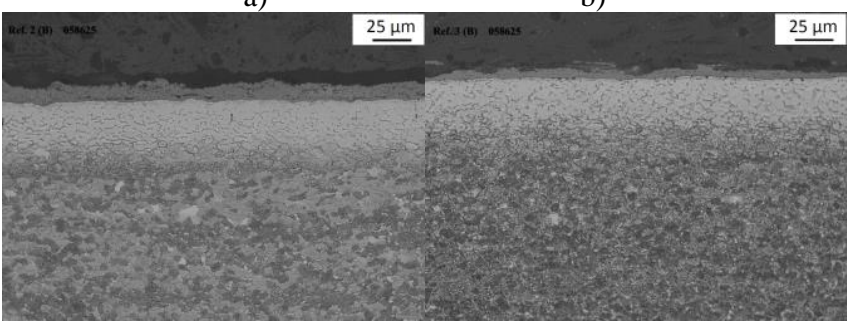

c)

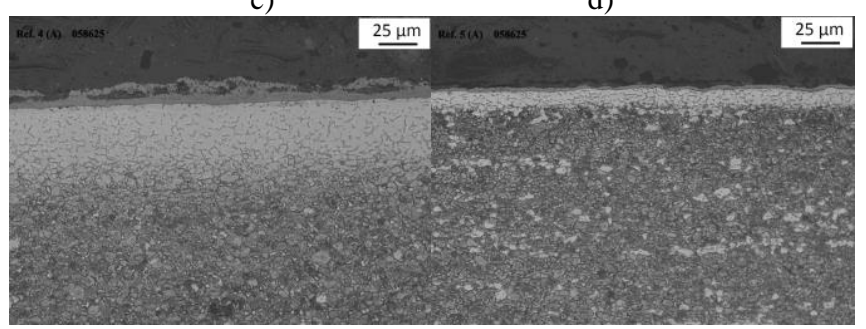

e)

f)

Fig. 22 Microstructure of Ti-6Al-4V: a) As-received, Ref.0 / b) Ref.1, c) Ref.2, d) Ref.3, e) Ref.4 and f) Ref.5 extracted from a previously heated and formed sample (400x magn.)

\subsubsection{Hardness}

The following chart, Table 9, shows the results of the Vickers hardness testing performed on the center of $\mathrm{T}$ and $\mathrm{L}$ sections of each Reference ( 0 to 5 ) shown in Fig. 7. The average values of the testing are displayed on the table.

Table 9 Results and average values of the Vickers hardness measurements of the Ref. 0 to 5 in both $\mathrm{T}$ and $\mathrm{L}$ sections

\begin{tabular}{|c|c|c|c|c|c|c|c|c|c|c|c|}
\hline \multicolumn{10}{|c|}{ References } \\
\hline \multicolumn{1}{|c|}{ 0 } & \multicolumn{1}{|c|}{$\mathbf{1}$} & \multicolumn{2}{c|}{2} & \multicolumn{2}{|c|}{3} & \multicolumn{2}{|c|}{} & \multicolumn{2}{|c|}{5} \\
\hline $\mathrm{T}$ & $\mathrm{L}$ & $\mathrm{T}$ & $\mathrm{L}$ & $\mathrm{T}$ & $\mathrm{L}$ & $\mathrm{T}$ & $\mathrm{L}$ & $\mathrm{T}$ & $\mathrm{L}$ & $\mathrm{T}$ & $\mathrm{L}$ \\
\hline 322 & 349 & 335 & 321 & 321 & 320 & 319 & 323 & 318 & 324 & 323 & 324 \\
\hline 323 & 343 & 329 & 317 & 321 & 313 & 325 & 314 & 326 & 325 & 320 & 339 \\
\hline 323 & 339 & 321 & 321 & 328 & 320 & 316 & 319 & 329 & 313 & 320 & 331 \\
\hline \multicolumn{10}{|c|}{ Average values } \\
\hline 323 & 344 & 328 & 320 & 323 & 318 & 320 & 319 & 324 & 321 & 321 & 331 \\
\hline
\end{tabular}

The values obtained in the sections perpendicular to the tool advance $(\mathrm{T})$ are slightly higher in all the sections affected by the tool working (Ref. 1 - Ref. 4), as presented by Ortiz et al., ${ }^{27}$ due to the grain stretching along the feeding direction of the tool. Opposite to this, Ref. 0 (as-received material) and Ref. 5 show higher L section values, than of $\mathrm{T}$, being $\mathrm{L}$ values the ones associated with the perpendicular section to the rolling direction for Ref. 0. However, in the case of Ref. 5, the difference between $\mathrm{L}$ and $\mathrm{T}$ sections is not sizeable and suggests that a slight softening of the material is produced due to high process temperatures. In all the areas studied of the processed part (Ref. 1 - Ref. 5) the microhardness does not vary significantly, just slightly, and it can be considered quite homogenous throughout the piece contrary to what happens in the study of Najafabady and Ghaei ${ }^{10}$ where a local-dynamic electric heating is used and consequently the hardness increases considerably from the flange to the vertex of the analysed part. In the present work, the homogeneous behaviour of the microhardness is in concordance with the results of microstructure shown above where no significantly different grain morphology among the studied zones is observed.

\section{Conclusions}

The present work focuses on the determination of the optimal working temperature conditions to form Ti-6Al-4V parts by global hot SPIF by using a supporting chamber and a clamping frame both equipped with electrical heaters. A set of heating and SPIF trials were carried out pointing out that:

- The homogeneity of the temperature distribution over the sheet improves when heating at small temperature increments and consequently the sheet deviation is reduced. The improvement is more significant when heating along a longer time since it leads to a higher homogeneity and as a result to lower deviations.

- As the working temperature increases the geometric accuracy of the fabricated part increases since the deviations related to the springback effect are reduced. Sheet temperatures above $650{ }^{\circ} \mathrm{C}$ are recommendable to significantly enhance geometric accuracy of Ti-6Al-4V parts. However, in general, temperature increase has a negative effect on the part perimeter area which shows higher deviations due to bending as a result of lower stiffness of the sheet flange at higher temperatures.

- Uniform temperature during forming also contributes to low distortions when part trimming since lower thermal stresses are induced. In any case, a controlled cooling down is necessary to ensure that the production cycle remains free from thermal loads. By introducing an adequate stress relief treatment, the effect of the localized action of the forming tool can be counteracted and final distortion after trimming is low.

- The alpha-case thickness analysis confirms a uniform alpha-case layer in all the studied strained zones. Furthermore, both microstructure and hardness do not present relevant variations between the measurements on the several references carried out. These results point out a homogeneity of the analysed postforming material properties along the entire part, highlighting that 
differences in strain due to geometry and slight temperature inhomogeneities do not generate significant divergences in the alpha-case, microstructure and hardness of the resulting part.

Despite the improvements presented in the geometric accuracy, further progress is needed to produce accurate Ti-6Al-4V parts by hot SPIF using the system proposed. Thus, the deviations on the part perimeter area must be reduced. The use of a backing plate seems necessary in this sense. Furthermore, a higher homogeneity between temperatures of the clamped and free to form areas seems also reasonable. On the other hand, the combined use of the system and procedures proposed in this paper with a tool path correction algorithm appears as the adequate solution to achieve acceptable accuracies.

\section{ACKNOWLEDGEMENT}

Research leading to these results was done within the project INMA - Innovative manufacturing of complex titanium sheet components. This project has received funding from the European Union's Seventh Framework Programme for research, technological development and demonstration under grant agreement No. 266208.

\section{REFERENCES}

1. Groche, P. et al., "Incremental Bulk Metal Forming," CIRP Annals, Vol. 56, pp. 635-656, 2007.

2. Do, V.-C., Nguyen, D.-T., Cho, J.-H. \& Kim, Y.-S., "Incremental forming of 3D structured aluminum sheet," International Journal of Precision Engineering and Manufacturing, Vol. 17, pp. 217-223, 2016.

3. Behera, A. K., de Sousa, R. A., Ingarao, G. \& Oleksik, V., "Single point incremental forming: An assessment of the progress and technology trends from 2005 to 2015," Journal of Manufacturing Processes, Vol. 27, pp. 37-62, 2017.

4. Matthew J. Donachie., "TITANIUM A Technical Guide," ASM International, 2004.

5. Duflou, J. R., Callebaut, B., Verbert, J. \& De Baerdemaeker, H., "Laser Assisted Incremental Forming: Formability and Accuracy Improvement," CIRP Annals, Vol. 56, pp. 273-276, 2007.

6. Göttmann, A. et al., "Laser-assisted asymmetric incremental sheet forming of titanium sheet metal parts," Prod. Eng. Res. Devel., Vol. 5, pp. 263-271, 2011.

7. Fan, G., Sun, F., Meng, X., Gao, L. \& Tong, G., "Electric hot incremental forming of Ti-6Al-4V titanium sheet," Int J Adv Manuf Technol, Vol. 49, pp. 941-947, 2010.

8. Ambrogio, G., Filice, L. \& Gagliardi, F., "Formability of lightweight alloys by hot incremental sheet forming," Materials \& Design, Vol. 34, pp. 501-508, 2012.

9. Honarpisheh, M., Abdolhoseini, M. J. \& Amini, S., "Experimental and numerical investigation of the hot incremental forming of Ti6Al-4V sheet using electrical current," The International Journal of Advanced Manufacturing Technology, Vol. 83, pp. 2027-2037, 2016.

10. Najafabady, S. A. \& Ghaei, A., "An experimental study on dimensional accuracy, surface quality, and hardness of Ti-6Al-4 V titanium alloy sheet in hot incremental forming," The International Journal of Advanced Manufacturing Technology, Vol. 87, pp. 3579-3588, 2016.

11. Nguyen-Tran, H.-D. et al., "A review of electrically-assisted manufacturing," International Journal of Precision Engineering and Manufacturing-Green Technology, Vol. 2, pp. 365-376, 2015.

12. Asghar, J. \& Nallagundla, V. R., "Importance of Tool Configuration in Incremental Sheet Metal Forming of Difficult to Form Materials using Electro-Plasticity," Proceedings of the World Congress on Engineering, Vol. 3, 2013.

13. Asgar, J., Lingam, R. \& Reddy, V. N., "Tool path influence on electric pulse aided deformation during incremental sheet metal forming," AIP Conference Proceedings, Vol. 1567, pp. 840-843, 2013.

14. Ambrogio, G., Filice, L. \& Manco, G. L., "Warm incremental forming of magnesium alloy AZ31," CIRP Annals, Vol. 57, pp. 257-260, 2008.

15. Ji, Y. H. \& Park, J. J., "Formability of magnesium AZ31 sheet in the incremental forming at warm temperature," Journal of Materials Processing Technology, Vol. 201, pp. 354-358, 2008.

16. JI, Y. H. \& PARK, J. J., "Incremental forming of free surface with magnesium alloy AZ31 sheet at warm temperatures," Transactions of Nonferrous Metals Society of China 18, Supplement 1, s165s169, 2008.

17. Zhang, Q. et al., "Influence of anisotropy of the magnesium alloy AZ31 sheets on warm negative incremental forming," Journal of Materials Processing Technology, Vol. 209, pp. 5514-5520, 2009.

18. Zhang, Q. et al., "Warm negative incremental forming of magnesium alloy AZ31 Sheet: New lubricating method," Journal of Materials Processing Technology, Vol. 210, pp. 323-329, 2010.

19. Khazaali, H. \& Fereshteh-Saniee, F., "A comprehensive experimental investigation on the influences of the process variables on warm incremental forming of Ti- $6 \mathrm{Al}-4 \mathrm{~V}$ titanium alloy using a simple technique," The International Journal of Advanced Manufacturing Technology, Vol. 87, pp. 2911-2923, 2016.

20. Palumbo, G. \& Brandizzi, M., "Experimental investigations on the single point incremental forming of a titanium alloy component 
combining static heating with high tool rotation speed," Materials \& Design, Vol. 40, pp. 43-51, 2012.

21. Khan, M. et al., "An intelligent process model: predicting springback in single point incremental forming," The International Journal of Advanced Manufacturing Technology, Vol. 76, pp 2071-2082, 2015.

22. Fiorentino, A., Giardini, C. \& Ceretti, E., "Application of artificial cognitive system to incremental sheet forming machine tools for part precision improvement," Precision Engineering, Vol. 39, pp. 167-172, 2015.

23. Zwierzycki, M., Nicholas, P. \& Ramsgaard Thomsen, M., "Localised and Learnt Applications of Machine Learning for Robotic Incremental Sheet Forming," In: De Rycke K. et al., (eds) Humanizing Digital Reality, Springer, Singapore, pp. 373-382, 2018.

24. Azevedo, N. G. et al., "Lubrication aspects during Single Point Incremental Forming for steel and aluminum materials," International Journal of Precision Engineering and Manufacturing, Vol. 16, pp. 589-595, 2015.

25. Lu, B. et al., "Mechanism investigation of friction-related effects in single point incremental forming using a developed oblique roller-ball tool," International Journal of Machine Tools and Manufacture, Vol. 85, pp. 14-29, 2014.

26. Xu, D. et al., "Mechanism investigation for the influence of tool rotation and laser surface texturing (LST) on formability in single point incremental forming," International Journal of Machine Tools and Manufacture, Vol. 73, pp. 37-46, 2013.

27. M.Ortiz, M.L.Penalva, M.J.Puerto, P.Homola \& V.Kafka., "Hot Single Point Incremental Forming of Ti-6Al-4V Alloy," Key Engineering Materials, Vols. 611-612, pp. 1079-1087, 2014.

28. Rudnev, V., "Successful induction heating of RCS billets," Forge Magazine, 2008.

29. Jeswiet, J. et al., "Asymmetric Single Point Incremental Forming of Sheet Metal," CIRP Annals, Vol. 54, pp. 88-114, 2005. 
Click here to access/download Supplementary Material Letter to the editor_24012019.pdf 